\title{
Two new species of stygobitic Anzcyclops (Copepoda: Cyclopoida: Cyclopidae) from Australia
}

\author{
Jane M. McRae 1,*, Tomislav Karanovic ${ }^{2}$ and Stuart A. Halse ${ }^{1}$ \\ ${ }^{1}$ Bennelongia Environmental Consultants, 5 Bishop Street, Jolimont Western Australia 6014, Australia. \\ 2 Department of Life Sciences, Hanyang University, Seoul 133-791, South Korea; Institute for Marine \\ and Antarctic Studies, University of Tasmania, Private Bag 129, Hobart Tasmania 7001, Australia. \\ * Corresponding author: jane.mcrae@bennelongia.com.au
}

\begin{abstract}
Two new, small subterranean species of the genus Anzcyclops Karanovic, Eberhard \& Murdoch, 2011 are described from the Pilbara region in Western Australia. Both Anzcyclops trotteri sp. nov. and Anzcyclops pearsoni sp. nov. have small known ranges. Both species are distinguished from all other described species of Anzcyclops by the highly ornamented hyaline fringe of the urosomal segments and the postero-lateral expansion of the genital somite dorsally. Anzcyclops trotteri sp. nov. can be distinguished from Anzcyclops pearsoni sp. nov. by its serrated (rather than smooth) W-shaped projection in the medial dorsal hyaline fringe of the genital double-somite of both sexes and more jagged serrations of the dorsal hyaline fringe of posterior urosomites, as well as by subtle differences in body shape and in segmentation of the antennule. A key to all known species of Anzcyclops is provided.
\end{abstract}

KEYWORDS: stygobite, stygofauna, Pilbara, taxonomy, biodiversity, short range endemic

\section{INTRODUCTION}

The genus Anzcyclops Karanovic, Eberhard \& Murdoch, 2011 was erected to contain five species that mostly share the following combination of characters: dorsoventrally compressed body shape, reticulated integument, and reduced armature of the antennule, antenna and swimming legs (with a spine formula of 2.3.3.2 or 2.3.2.2). Three of the existing species of Anzcyclops occur in the Pilbara region of northern Western Australia (Figure 1), one species is found in Queensland and one species is from New Zealand. In this paper, we describe a further two species of Anzcyclops from the Pilbara region. An eighth species is currently being described from India (Totakura \& Ranga Reddy, in press). It is not discussed further in this paper.

It is not surprising that three of the described species of Anzcyclops are known from the Pilbara. This region has been relatively well surveyed for stygofauna during the past 15 years, at least in the context of the Southern Hemisphere, and possibly about half the stygobitic species present have been formally described (Eberhard et al. 2009; Halse et al. 2014). With 86 named ostracod and 50 named copepod species, the ostracod and copepod faunas of the Pilbara are both rich and better known than other elements of the region's stygofauna (see Karanovic 2007; Karanovic and McKay 2010 for ostracods; Karanovic 2006, 2010; Karanovic and Hancock 2009; Karanovic and Krajicek 2012; Tang et al. 2008; Karanovic et al. 2011; Karanovic and McRae 2013 for copepods).

Threats to the conservation of stygofauna in the Pilbara are significant. Mining, principally for iron ore, is the main economic activity in the region and extensive de-watering of mine pits is often required to access ore (Johnson and Wright 2001; Sheppard et al. 2009). This de-watering may potentially threaten species with small ranges, which many species of stygofauna have. While some stygobitic copepod species are widely distributed (Karanovic and Krajicek 2012; Halse et al. 2014), others appear to have linear ranges of only a few kilometres (e.g. Karanovic and Cooper 2011). Threats such as de-watering highlight the importance of documenting species distributions so that species with small ranges may be recognised and their conservation planned. Documenting distributions is much easier when species are formally described. 


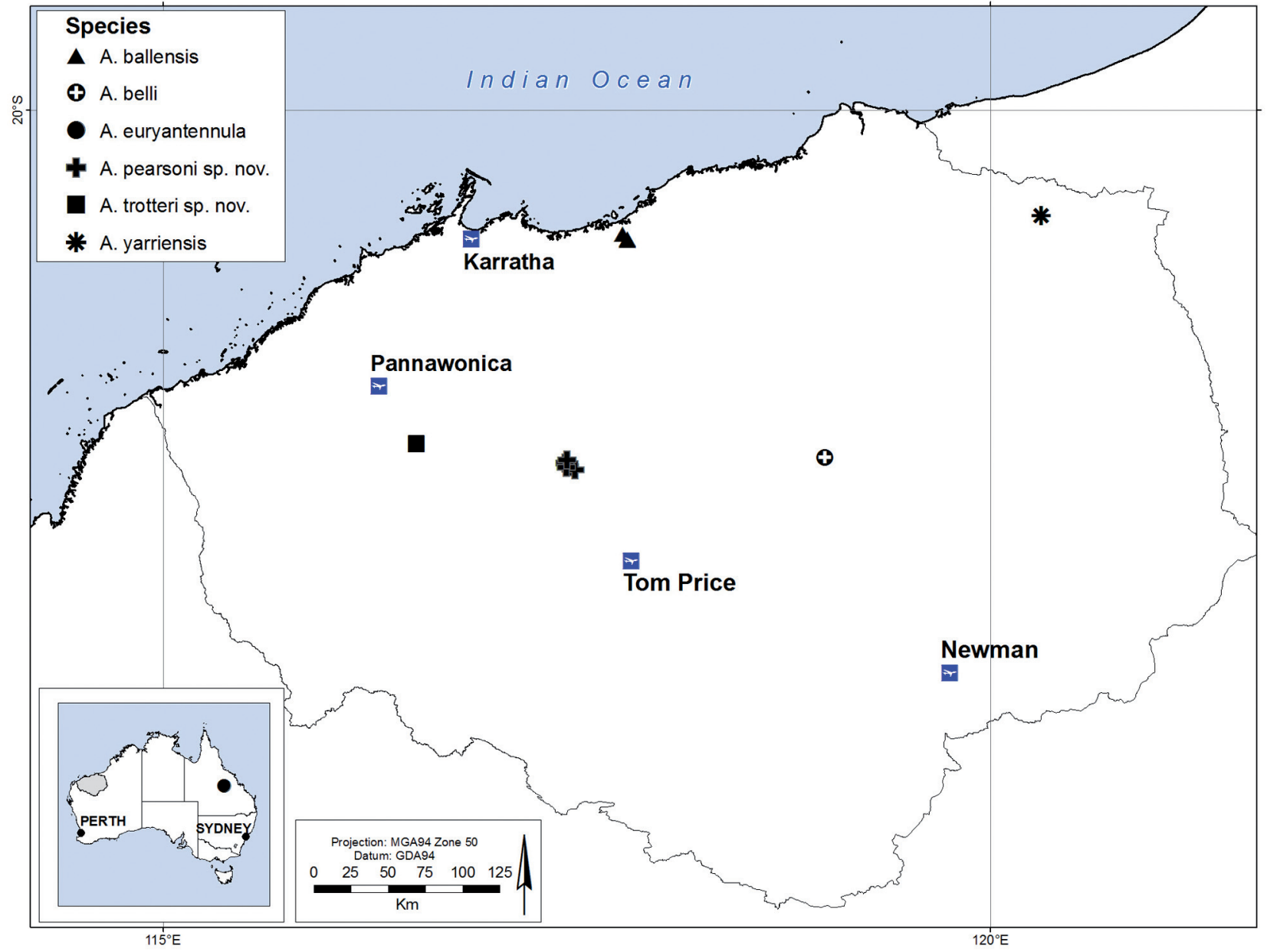

FIGURE 1 Known locations of Australian specimens of Anzcyclops.

\section{MATERIAL AND METHODS}

Both new species were collected from uncased holes drilled for geological exploration. These holes were sampled using a weighted haul net (mesh size 50 or $150 \mathrm{~m}$ ) that was lowered on cord to the bottom of the hole, jiggled to stir up the substrate and then retrieved through the water column and back to the surface (Eberhard et al. 2005). Most specimens were collected while sampling for stygofauna, although some were collected as bycatch when the watertable was intercepted while collecting troglofauna using a netting technique known as scraping (Halse and Pearson 2014). Nets were sterilised after use to prevent transfer of animals.

Samples were preserved in the field in $100 \%$ ethanol and returned to the laboratory for sorting. Appropriate specimens of the two species were dissected and mounted on microscope slides in Faure's medium (Stock and Von Vaupel Klein 1996) and dissected appendages were then sealed by a coverslip.
All drawings were prepared using a camera lucida attached to a Leica DM2500 differential interference compound microscope with N-PLAN objectives. Specimens that were drawn whole were examined in a mixture of equal parts of distilled water and glycerol and, after examination, were again preserved in $100 \%$ ethanol.

Specimens examined by scanning electron microscopy were dehydrated in progressive ethanol concentrations, transferred into pure isoamyl-acetate, critical-point dried, mounted on stubs, coated in gold and observed under a Hitachi S-4700 scanning electron microscope on the in-lens detector, with working distances of 12.7-13.2 $\mathrm{mm}$ and an accelerating voltage of $10 \mathrm{kV}$.

The morphological terminology used in this paper follows Huys and Boxshall (1991). All listed material is deposited in the Western Australian Museum (WAM), Perth. 
TABLE 1 Habitat data for Pilbara Anzcyclops species. $N=$ number of drill holes in which recorded.

${ }^{1}$ Depth to groundwater; ${ }^{2}$ Karanovic et al. (2012), ${ }^{3}$ Detrital iron deposit; ${ }^{4}$ Channel iron deposit.

\begin{tabular}{|c|c|c|c|c|c|}
\hline Species & $N$ & $\begin{array}{l}\mathrm{EC} \\
(\mu \mathrm{S} / \mathrm{cm})\end{array}$ & $\mathrm{pH}$ & $\begin{array}{l}\text { Depth }^{1} \\
\text { (m) }\end{array}$ & Aquifers intersected \\
\hline A. ballensis ${ }^{1,2}$ & 3 & - & - & - & Alluvium, fractured basalt \\
\hline A. belli ${ }^{2}$ & 1 & 820 & 6.9 & 12.5 & Jointed basalt \\
\hline A. pearsoni sp. nov. & 6 & $203-879$ & $6-6.7$ & $26-33$ & Alluvium, $\mathrm{DID}^{3}, \mathrm{CID}^{4}$ \\
\hline A. trotteri sp. nov. & 1 & 300 & 6.4 & 25 & Alluvium, DID, CID \\
\hline A. yarriensis $^{2}$ & 1 & 427 & 5.8 & 40.1 & Hematite, fractured basalt \\
\hline
\end{tabular}

\section{SYSTEMATICS}

\section{Family Cyclopidae Burmeister, 1834}

\section{Genus Anzcyclops Karanovic, Eberhard \& Murdoch, 2011}

\section{Anzcyclops trotteri sp. nov.}

(Figures 2-6)

http://www.zoobank.org/urn:Isid:zoobank. org:act:77309487-733A-4F37-B626-12EFF5C4D75F

\section{MATERIAL EXAMINED}

\section{Holotype}

Australia: Western Australia: female, Pilbara region, Robe River catchment, drill hole BH209, 2200'57"S $116^{\circ} 31^{\prime} 58.6^{\prime \prime}$ E, S. Bennett \& G. Pearson, 19 July 2012 (WAM C55886, dissected on slide). Depth to watertable $25 \mathrm{~m}$, water temperature $26.4{ }^{\circ} \mathrm{C}, \mathrm{pH} 6.42$, electrical conductivity $300 \mu \mathrm{S} / \mathrm{cm}$ (Table 1 ).

\section{Allotype}

Australia: Western Australia: male, Pilbara region, Robe River catchment, drill hole BH209, 22 ${ }^{\circ} 00^{\prime} 57^{\prime \prime} \mathrm{S}$ $116^{\circ} 31^{\prime} 58.6^{\prime \prime}$ E, S. Bennett \& G. Pearson, 19 July 2012 (WAM C55887, dissected on slide).

\section{Paratypes}

Australia: Western Australia: Pilbara region, Robe River catchment, drill hole BH209, 2200'57"S $116^{\circ} 31^{\prime} 58.6^{\prime \prime} \mathrm{E}, \mathrm{S}$. Bennett \& G. Pearson, 19 July 2012, 41 males and females in alcohol (WAM C55888); 1 female (WAM C55889, dissected on slide); 1 female (WAM C57230, dissected on slide); 2 males and 3 females (WAM C55891) on one SEM stub; G. Pearson \& J. Quartermaine, 5 October 2012 (WAM C55901), 1 female in alcohol; 1 male and 1 female (WAM C55890, dissected on slide); 3 males and 11 females in alcohol (WAM C60015).

\section{DIAGNOSIS}

Anzcyclops trotteri sp. nov. differs from previously described species of Anzcyclops in the pronounced ornamentation of the somites (all other described species have smooth somites) and large spine-like postero-lateral projections of the dorsal side of the genital doublesomite, the triangular operculum (other species have a rounded operculum), the lack of the apical spine on the second endopodal segment of the fourth swimming leg (instead there is an apical secondary seta) that is characteristic of other species except for $A$. belli Karanovic, Eberhard \& Murdoch, 2011 and A. pearsoni sp. nov. The serrated $\mathrm{W}$-shaped projection in the medial dorsal hyaline fringe of the genital double-somite of both sexes, and more jagged serrations of the dorsal hyaline fringe of posterior urosomites, distinguish $A$. trotteri sp. nov. from $A$. pearsoni sp. nov.

\section{DESCRIPTION}

\section{Female}

Total body length of females from tip of rostrum to end of the caudal rami ranges from $282-320 \mathrm{~m}$ (mean $301 \mathrm{~m} ; \mathrm{n}=9$ ). Habitus robust, dorsoventrally compressed, with prosome/urosome ratio 1.7 and greatest width at posterior end of cephalothorax (Figures 2A, B, 5A). Body length/width ratio about 2.1 (dorsal view); cephalothorax 1.4 times as wide as genital double-somite. Free pedigerous somites with slight lateral expansions but an overall form that is typical of the genus. Nauplius eye visible. Rostrum large, membranous, broadly rounded, and furnished with 2 large sensilla (Figure 5B). Cephalothorax slightly longer than greatest width (dorsal view), representing $50 \%$ of total body length. Surface of cephalothoracic shield and pleurotergites of free pedigerous prosomites (except for second) with many large sensilla; integumental reticular pattern present on all somites but absent from appendages; hyaline fringes of somites narrow and smooth (Figure 2A). Fifth pedigerous somite ornamented with 2 dorsal sensilla; lateral edges of the somite with rounded tips or weakly recurved (Figure 2D). 

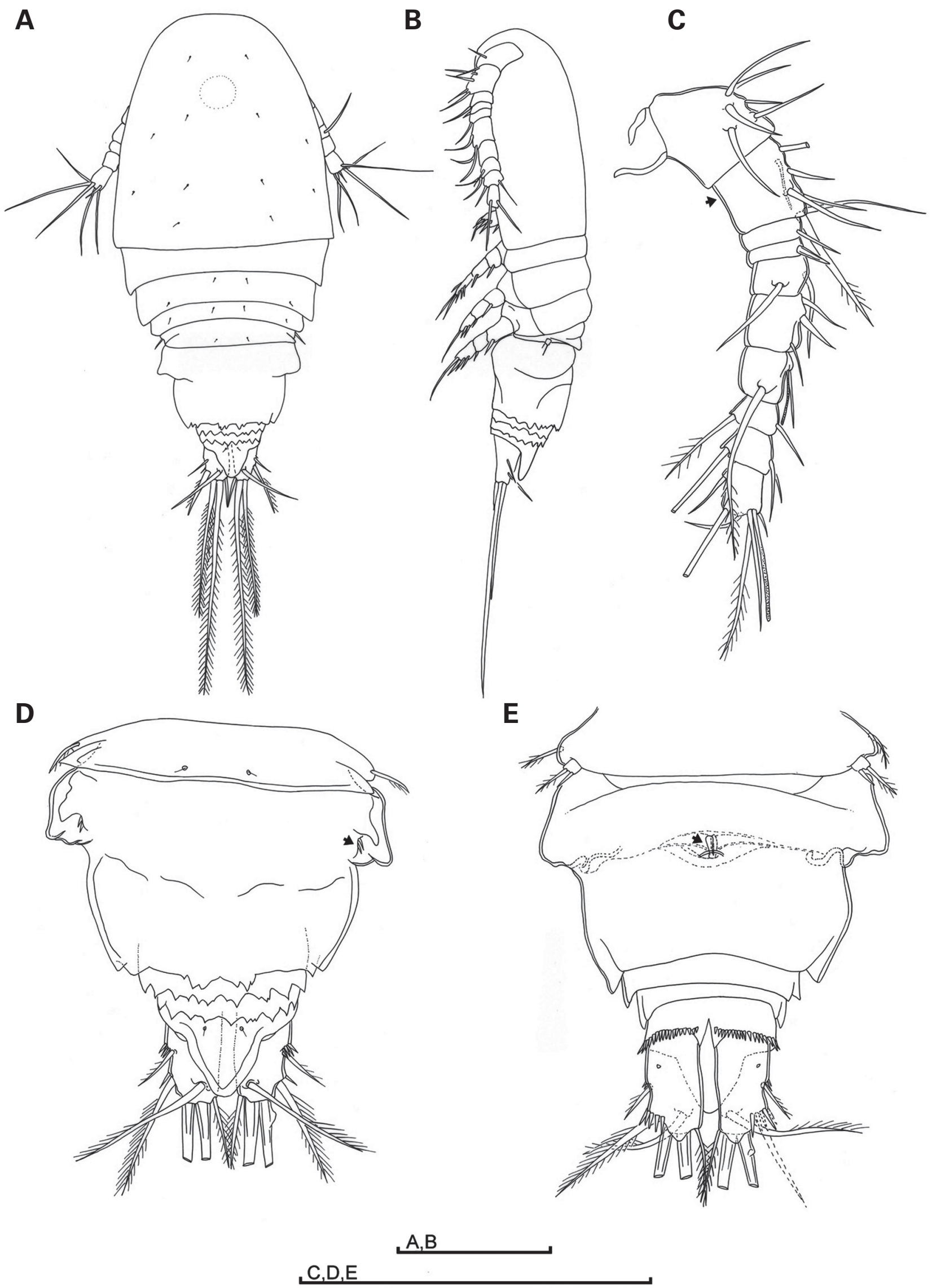

FIGURE 2 Anzcyclops trotteri sp. nov. Holotype female. A, habitus, dorsal; B, habitus, lateral; C, antennule, ventral; D, urosome, dorsal; E, urosome, ventral. Scale bars $0.1 \mathrm{~mm}$. 
A

B
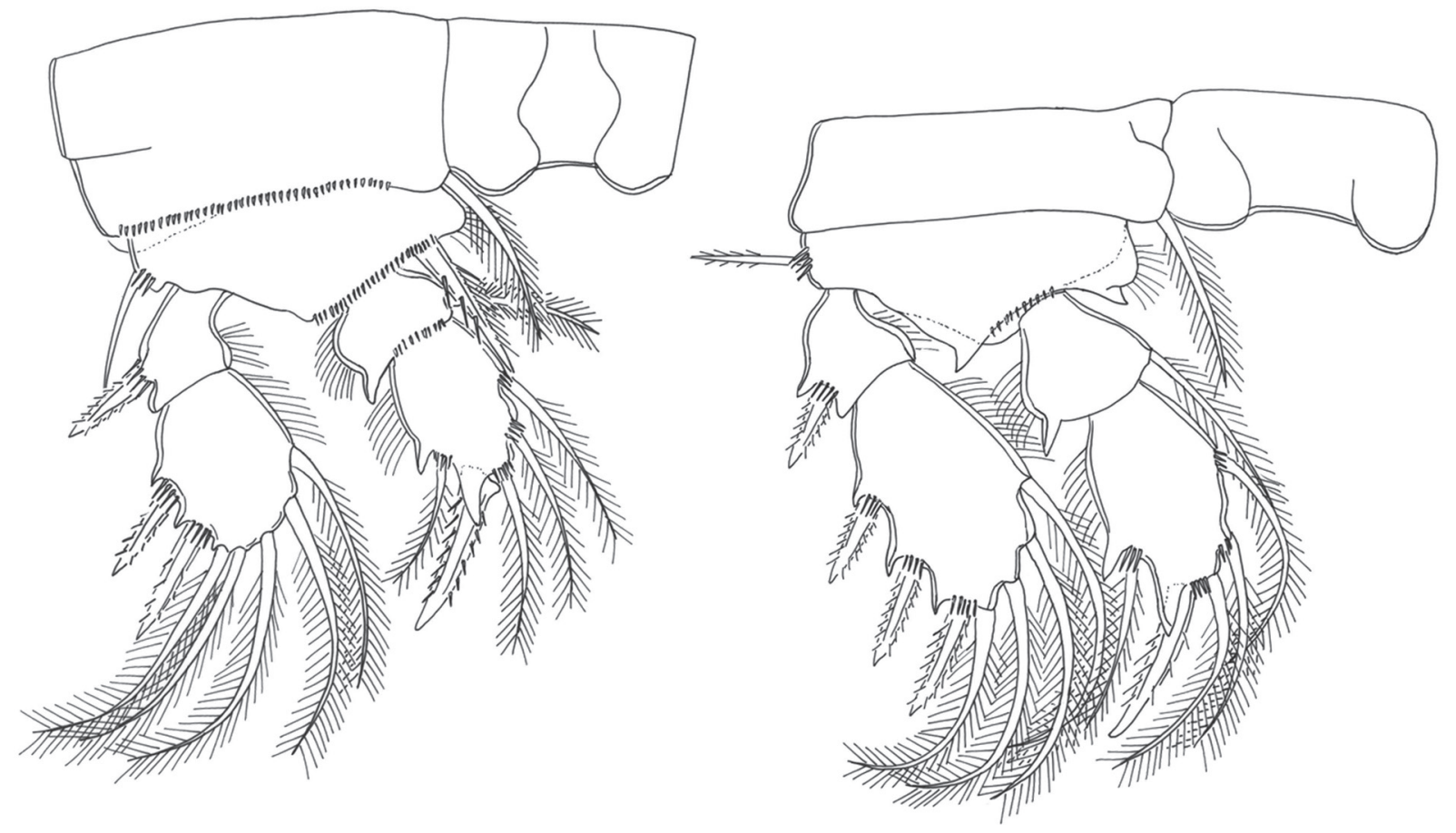

C

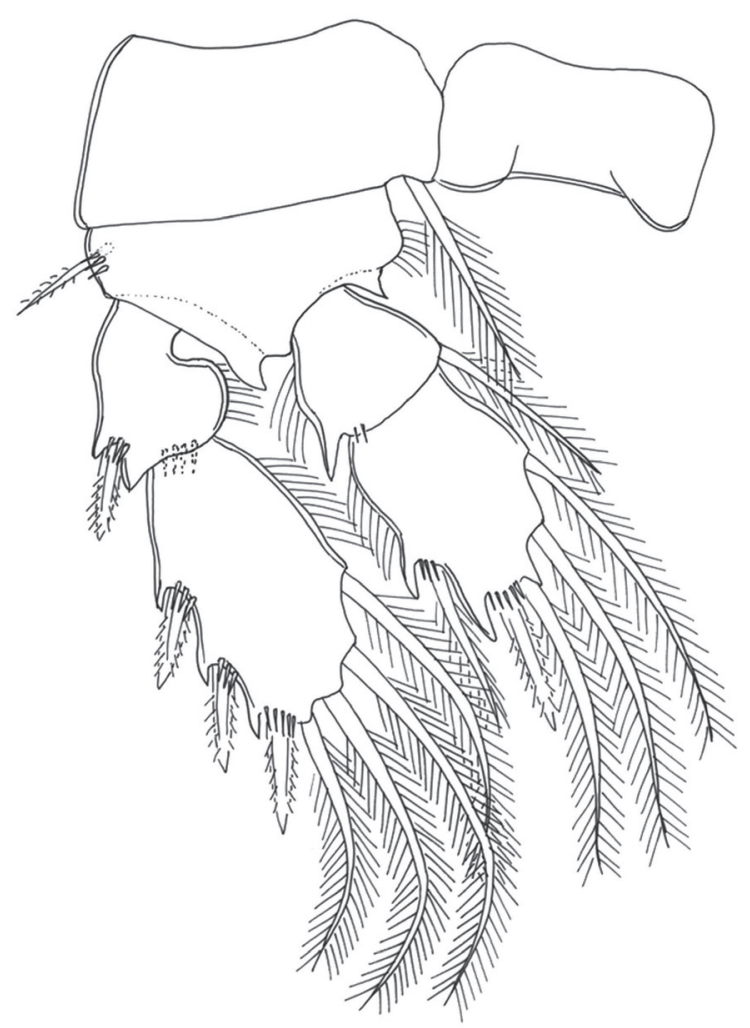

D

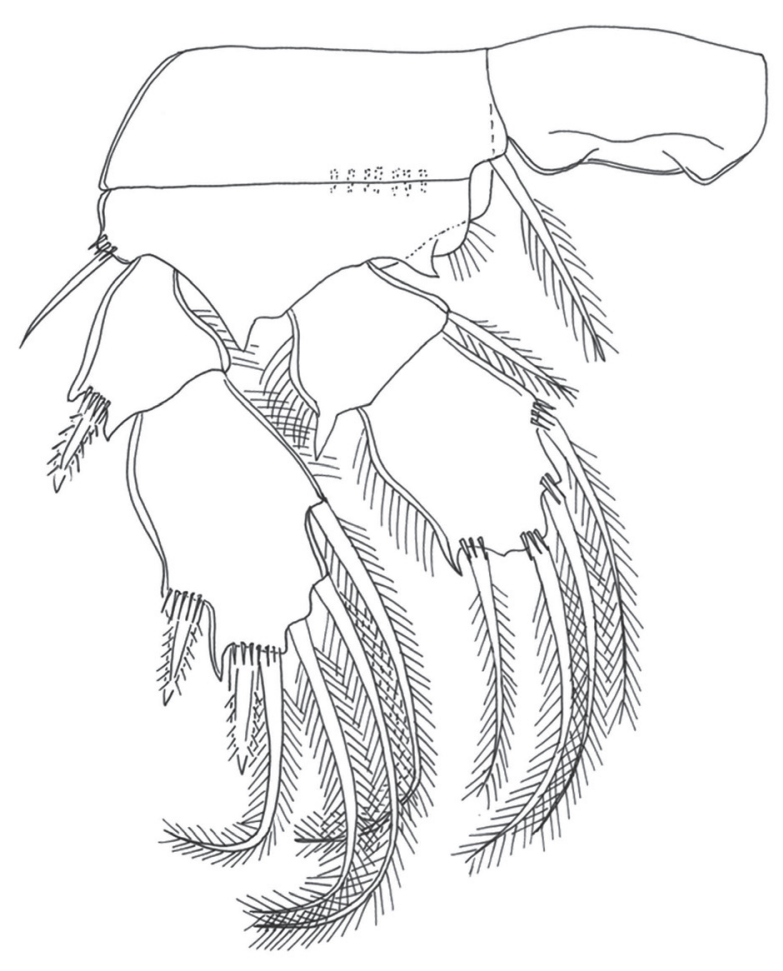

FIGURE 3 Anzcyclops trotteri sp. nov. A, first swimming leg, anterior, holotype female; B, second swimming leg, anterior, paratype (WAM C55890); C, third swimming leg, anterior, paratype (WAM C55890); D, fourth swimming leg, anterior, paratype (WAM C55889). Scale bar $0.1 \mathrm{~mm}$. 
A
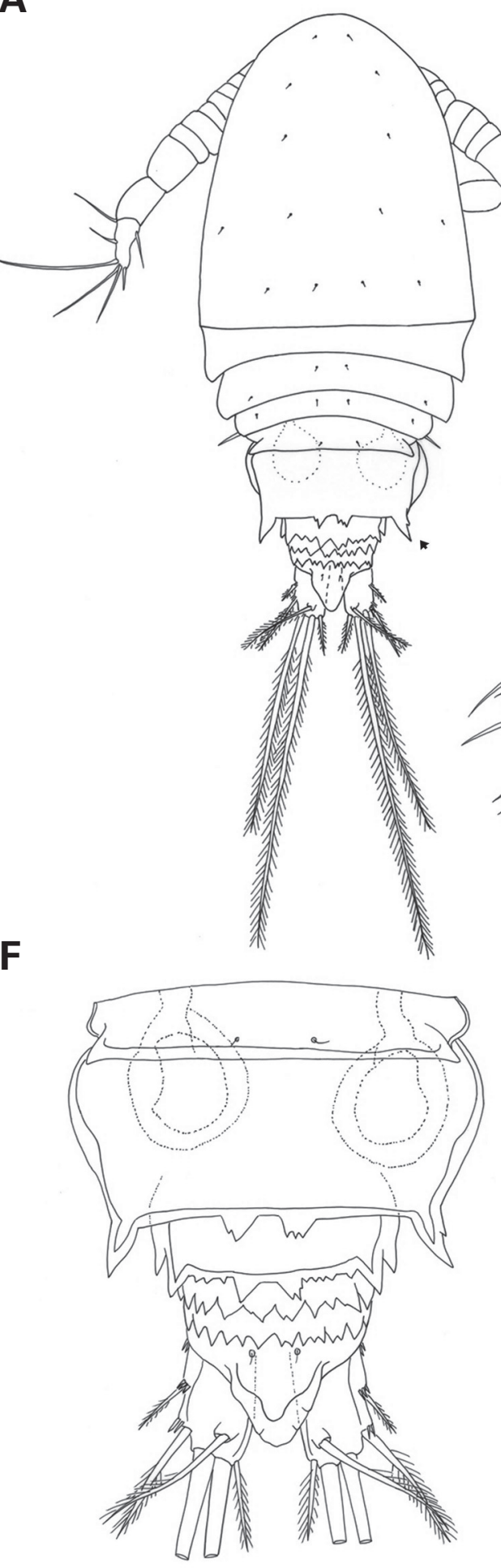

B

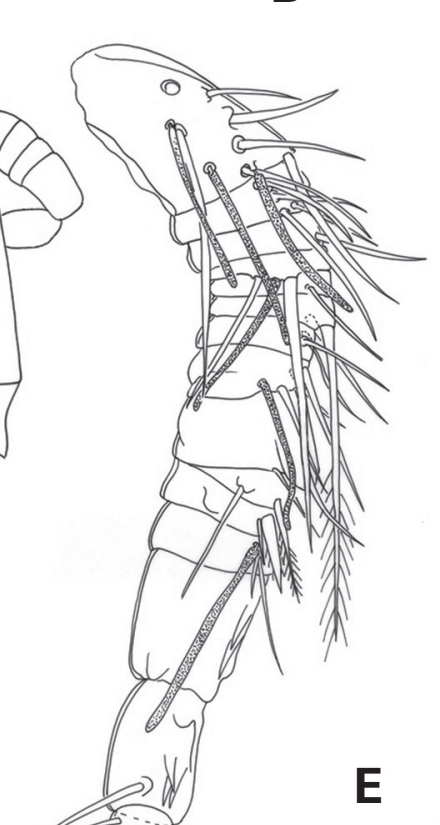

C
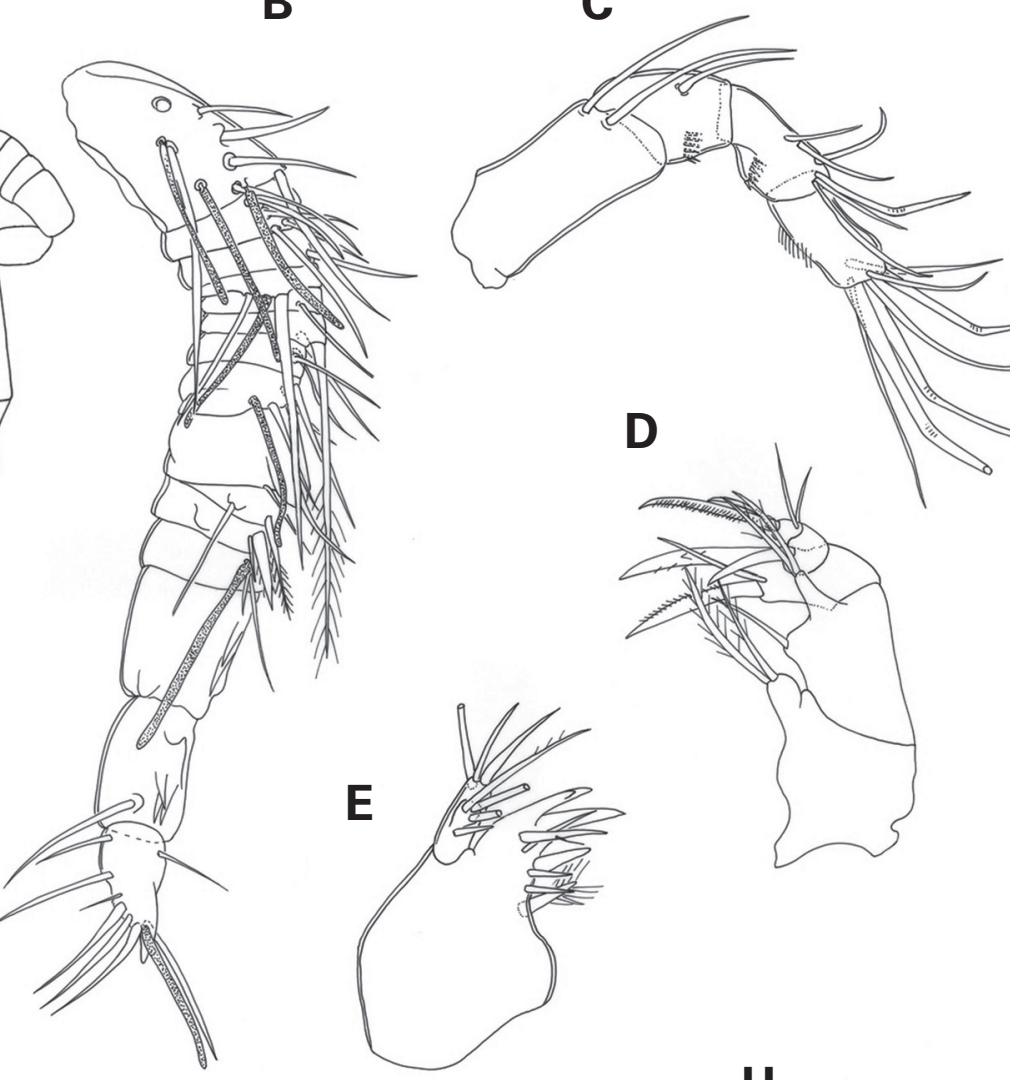

D
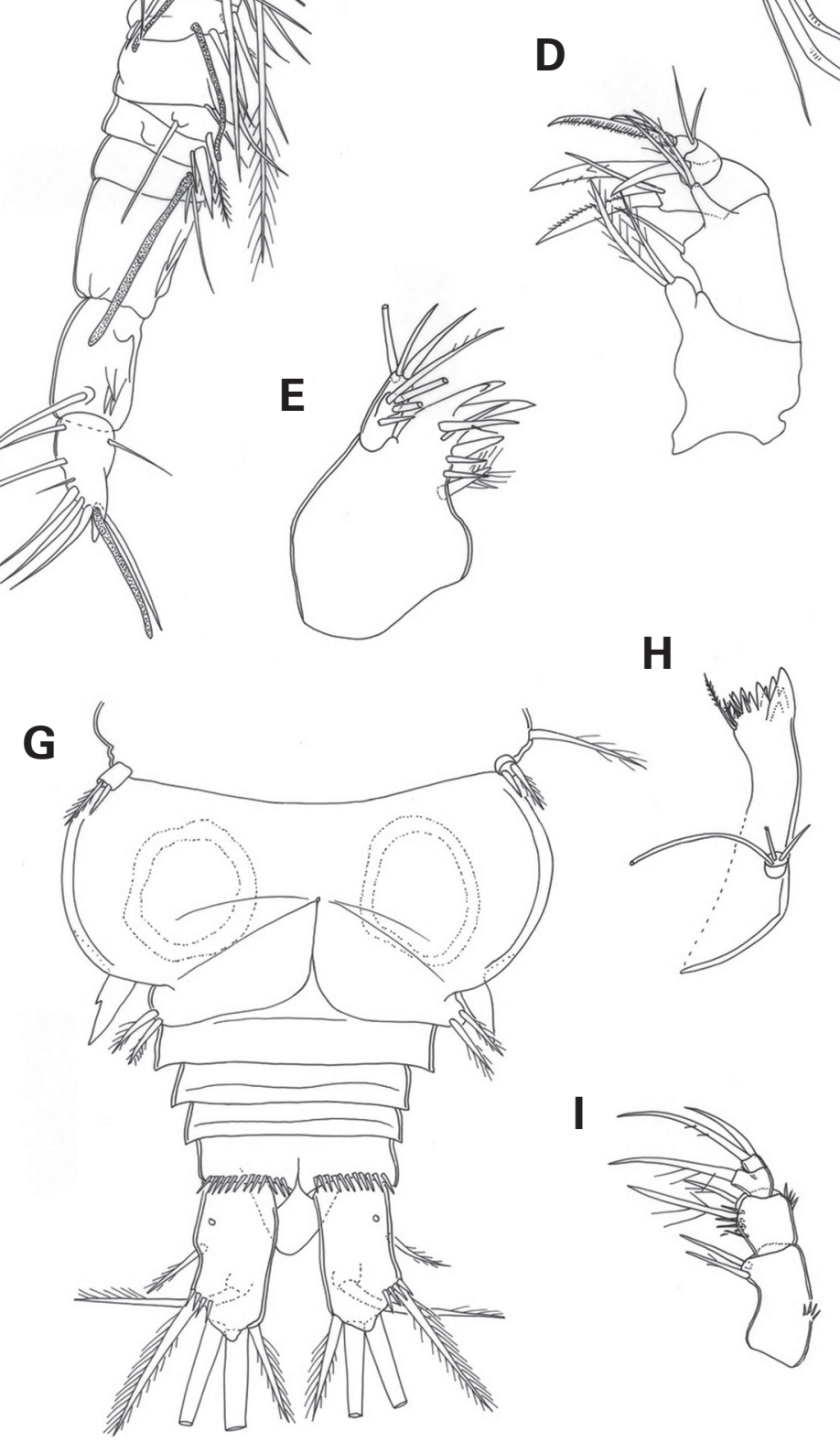

A

B-I

FIGURE 4 Anzcyclops trotteri sp. nov. A, B, F, G allotype male. A, habitus, dorsal; B, antennule, dorsal; C, antenna, caudal, paratype (WAM C55889); D, maxilla, posterior, paratype (WAM C57230); E, maxillule, anterior, holotype female; F, urosome, dorsal; G, urosome, ventral; H, mandible, posterior, paratype female (WAM C55889); I, maxilliped, anterior, paratype female (WAM C55890). Scale bars $0.1 \mathrm{~mm}$. 

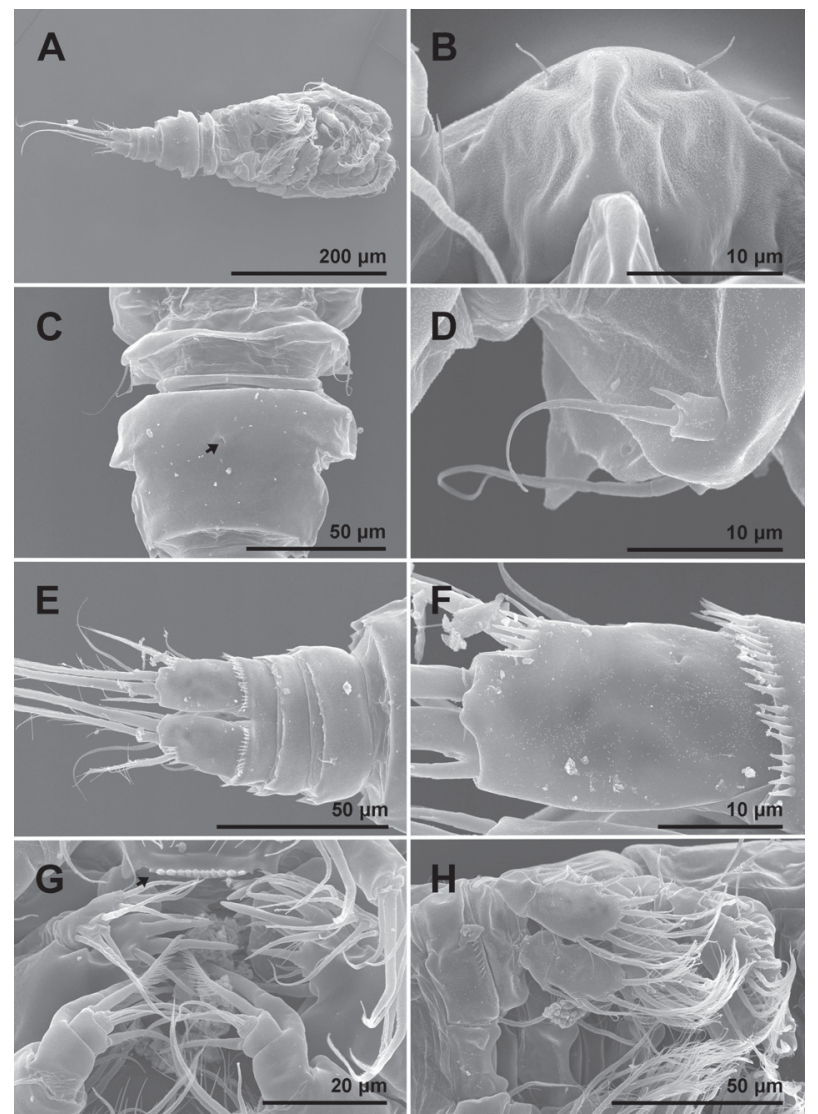

FIGURE 5 Anzcyclops trotteri sp. nov. SEM micrographs (WAM C55891), paratype female 7: A, habitus, ventral; B, rostrum, ventral; $C$, fifth pedigerous somite and genital double-somite, ventral; D, fifth leg, ventral; E, last three urosomites and caudal rami, ventral; F, right caudal ramus, ventral; $\mathrm{G}$, distal tips of mouth appendages, ventral; $H$, fourth swimming leg, posterior.
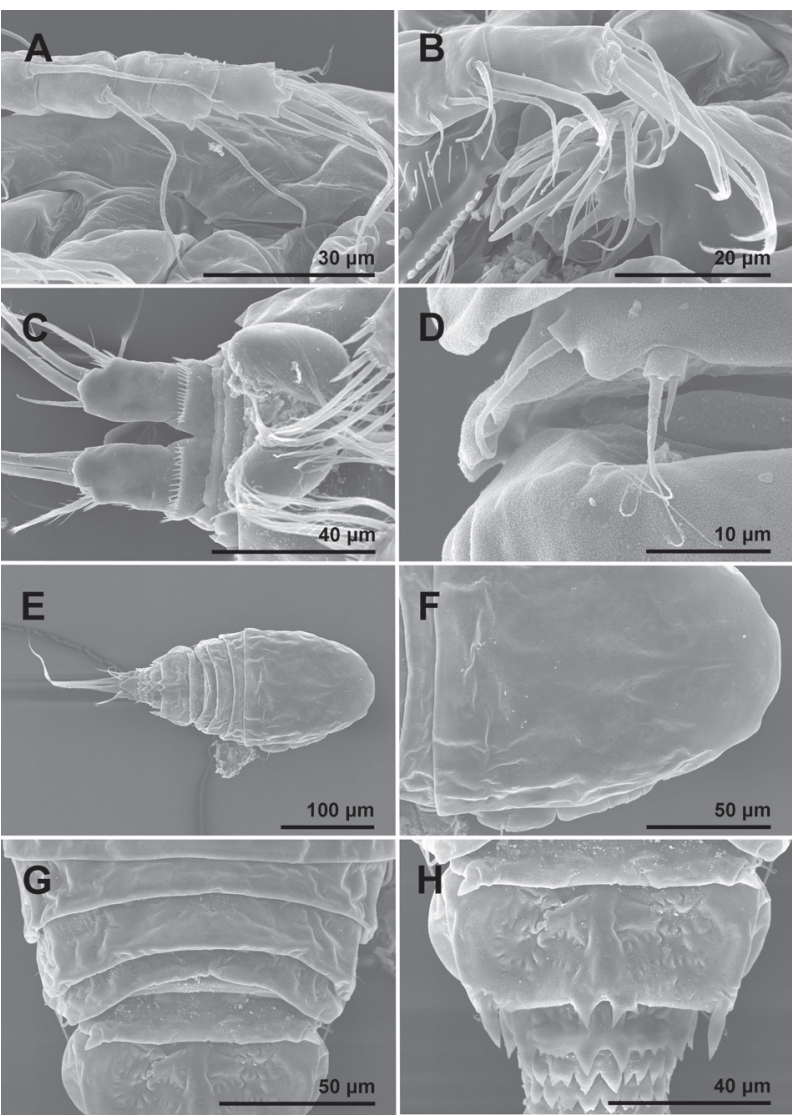

FIGURE 6 Anzcyclops trotteri sp. nov., SEM micrographs (WAM C55891), A, B, E-H paratype female 7; $\mathrm{C}$, paratype female 8 , D, paratype female 9; $\mathrm{E}-\mathrm{H}$, paratype male 1. A, distal part of antennula, ventral; B, distal part of antenna, ventral; $C$, urosome with spermatophores attached, ventral, paratype female 2; D, fifth leg, ventro-lateral, paratype female 3 ; $E$, habitus, dorsal; $F$, cephalothorax, dorsal; $G$, tergites of free pedigerous somites, dorsal; $\mathrm{H}$, anterior part of urosome, dorsal.

lateral transverse row of minute spinules along posterior margin (Figures 2D, E, 5E). Anal sinus smooth. Anal operculum very large, triangular, smooth, representing $62 \%$ of anal somite width. Caudal rami (Figures 2D, E, $5 \mathrm{E}, \mathrm{F})$ cylindrical, parallel, closely spaced, and about 2 times as long as wide; ornamented with a pore on ventral side in anterior lateral position and several spinules at base of the 2 lateral setae. Dorsal seta 1.2 times longer than ramus, inserted at $3 / 4$ of ramus length, biarticulate at base and plumose at distal part. Anterolateral seta arising dorsolaterally at about $1 / 2$ length of ramus, $1 / 3$ as long as dorsal seta. Posterolateral seta stout, spiniform, about the same length as ramus, bipinnate. Terminal accessory seta (innermost 1) also bipinnate but not spiniform, 0.5 times as long as posterolateral seta. Terminal setae without breaking planes and plumose; inner seta 1.5 times as long as outer seta and 0.47 times as long as body length. 
Antennule (Figures 2C, 6A) reaching 5/6 of cephalothoracic shield in length, 10-segmented, with ancestral second and third segments joined (arrowed in Figure 2C), with armature formula (ae $=$ aesthetasc): 6.7.1.1.2.3.2+ae.2.3.6+ae. Armature elements with 1 pinnate setae on the second, seventh, eighth and terminal segments, all other setae smooth. Apical aesthetasc somewhat longer than ultimate and penultimate segments combined. Length ratio of segments: $1.0: 1.0: 0.3: 0.2: 0.5: 0.9: 0.8: 0.5: 0.7$ : 0.9 .

Antenna 4-segmented, comprising coxobasis and 3-segmented endopod (Figures 4C, 6B). Coxobasis large, cylindrical, more than twice as long as wide, unornamented, armed with 2 smooth distomedial setae; seta representing exopod is absent. First endopodal segment ovoid, 1.4 times as long as wide, with inner smooth seta at $2 / 3$ and patch of spinules along lateral margin. Second endopodal segment more slender, 1.8 times as long as wide, with proximal part bearing 6 medial setae and 1 spinular row on lateral margin. Third endopodal segment cylindrical, twice as long as wide, with 1 spinular row on lateral margin and armed with 7 smooth apical setae ( 3 of them strong and geniculate). Length ratio of antennal segments from proximal end: $1.0: 0.6: 0.6: 0.6$.

Labrum (arrowed in Figure 5G) small trapezoidal plate, ornamented with 2 diagonal, short rows of 9 long spinules on anterior surface. Cutting edge slightly concave, with 9 large and sharp teeth, 2 smaller outer teeth between produced rounded lateral corners.

Mandible composed of coxa and small palp (Figure $4 \mathrm{H})$. Coxal gnathobase cutting edge with 2 spinules on anterior surface and 5 apical teeth (ventralmost tooth strongest and quadridentate; second, third and fifth teeth bidentatae), and 2 setae on dorsal corner (dorsalmost seta bipinnate, 1.7 times as long as other unipinnate seta). Palp 1.2 times as wide as long, unornamented but armed with 3 apical setae: 2 long and plumose (broken in holotype) and 1 short and smooth.

Maxillule (Figure 4E) robust, composed of praecoxa and 2-segmented palp. Praecoxal arthrite bearing 4 very strong distal spines ( 2 fused at base, 1 smooth, 1 bidentate; 2 distinct at base, 1 sharp, and 1 spinulate), and 3 medial elements (proximal longest and plumose). Palp composed of coxobasis and endopod. Coxobasis with 1 proximal (exopodal) seta and 3 medial setae; endopod with 3 setae.

Maxilla (Figure 4D) 5-segmented, slender. Endite of praecoxa with 2 pinnate setae. Coxa unornamented; proximal endite represented by a knob with 1 smooth seta; distal endite elongate with 2 apical bipinnate setae. Basis expanded into robust claw, ornamented with 2 sub apical teeth and row of spinules; 2 setae at base of claw with strong seta as long as claw. Endopod 2-segmented; proximal segment armed with 1 robust, smooth seta; distal segment with 2 apical setae, 1 robust, with row or setules, other slender and smooth, 2 slender and smooth subapical setae.

Maxilliped (Figure 4I) 4 segmented, composed of syncoxa, basis, and 2-segmented endopod. Ornamentation consisting of 1 row of large spinules on syncoxa close to outer margin. Basis with 2 rows of spinules. Armature formula: 2.2.1.2.

Intercoxal sclerites of all swimming legs with concave distal margins and without any surface ornamentation. Praecoxae short and unornamented. Coxae of first leg ornamented with long distal row of minute spinules on anterior surface, coxa of fourth leg with short spinule row on posterior surface. Inner distal corner of basis of all legs ornamented with long setules and a few spinules at base of outer seta; median edge and inner distal corner of basis of second, third, and fourth legs with small sharp process. Basis of first leg with large inner spine reaching midway along second endopodal segment (Figure 3A), with a long row of minute spinules near the spine insertion.

Swimming legs with 2-segmented exopods and endopods (Figures 3A-D). Second exopodal segment spine formula 2.3.3.2 and setal formula 5.4.4.4. The complete armature formula is:

$\begin{array}{lllll} & \text { Coxa } & \text { Basis } & \text { Exopod } & \text { Endopod } \\ \text { Leg } 1 & 0-1 & 1-\mathrm{I} & \mathrm{I}-0 ; \mathrm{I}, \mathrm{I}+1,4 & 0-1 ; 1, \mathrm{I}+1,2 \\ \text { Leg 2 } & 0-1 & 1-0 & \mathrm{I}-0 ; \mathrm{II}, \mathrm{I}+1,3 & 0-1 ; 1, \mathrm{I}+1,2 \\ \text { Leg 3 } & 0-1 & 1-0 & \mathrm{I}-0 ; \mathrm{II}, \mathrm{I}+1,3 & 0-1 ; 1, \mathrm{I}+1,2 \\ \text { Leg 4 } & 0-1 & 1-0 & \mathrm{I}-0 ; \mathrm{I}, \mathrm{I}+1,3 & 0-1 ; 1,1,2\end{array}$

All setae on endopods and exopods slender and plumose; no modified setae observed. All spines strong and bipinnate. Exopods with long hairlike setules on inner margin; endopods with setules on outer margin; both rami additionally ornamented with minute spinules at base of each armature element. Second (Figure 3B) and third (Figure 3C) swimming legs very similar, except second exopodal segment of third leg somewhat larger than that of second leg and apical spine smaller. Endopod of fourth swimming leg (Figures 3D, 5H) as wide as exopod; second endopodal segment about 1.4 times as long as wide; apical spine absent.

Fifth leg held ventrolaterally, composed of protopod completely fused to somite and free exopod (Figures 2E, 6D). Protopodal seta slender, visible in dorsal view, without prominent setophore, unisetulate along outer margin. Exopod small and quadriform, about as wide as long, armed apically with outer bipinnate seta and inner smooth spine; seta about twice as long as adjacent spine, 3 times as long as segment and almost as long as protopodal seta.

Sixth leg positioned dorsolaterally (arrowed in Figure 2D), consists of a small, semicircular cuticular plate, armed with 2 short spines. 


\section{Male}

Body length of males ranges from 275-294 m (mean $285 \mathrm{~m} ; \mathrm{n}=9$ ). Habitus (Figures 4A, 6E) smaller and more slender than in female, prosome/ urosome ratio about 2.0 and greatest width at posterior end of cephalothorax. Body length/width ratio 2.2; cephalothorax (Figure 6F) about 1.5 times as wide as genital somite. Cephalothorax 1.1 times as long as wide (dorsal view), representing $51 \%$ of total body length. Ornamentation of prosomites and colour similar to female.

Genital somite (Figures 4F, G; 6H) almost twice as wide as long, hyaline fringe medially with an irregularly serrated medial W-shaped lobe as in the female, but produced into large spine-like, posterolateral caudal projections. Next three urosomites without any ornamentation, all with hyaline fringe sharply irregularly serrated, ventrally smooth; serrations on third urosome fringe larger medially and laterally.

Anal somite (Figures 4F, G) ornamented as in female; anal operculum somewhat narrower. Caudal rami (Figures 4F, G) with ventral cuticular pore proximally; remaining ornamentation same as in female. Terminal setae as in female except inner seta longer, being 0.55 times as long as body length.

Antennule (Figure 4B) digeniculate, 15-segmented, with spine-shaped cuticular structures on thirteenth and fourteenth elements (distal geniculation). Armature formula: 6 + 3ae.4.1.2 + ae.1.2.2.3 + ae.2.2.2.2+ ae.0.1.8 + ae. One pinnate setae on the sixth and tenth segment, all other setae smooth. Asthetasc on $12^{\text {th }}$ segment relatively large and extending almost to midway on $14^{\text {th }}$ segment.

Antenna, labrum, mandible, maxillule, maxilla, maxilliped, swimming legs, and fifth leg similar to those of female.

Sixth leg (Figure 4G) large, unornamented cuticular plate, armed with 2 bipinnate and subequal setae on outer distal corner (inner spine and outer seta on outer distal corner; both bipinnate and subequal).

\section{ETYMOLOGY}

The species is named after Andrew Trotter of Bennelongia Environmental Consultants in recognition of his valuable work in helping to understand subterranean fauna in Western Australia. Specific epithet in singular masculine genitive.

\section{VARIABILITY}

The cuticular ornamentation is very variable and may be more or less obvious according to the preservation of the animal. The characters of the genital double-somite may also be variable and the accessory tooth present on the left spine of the male allotype (arrowed in Figure 4A) is not seen in all animals.

\section{Anzcyclops pearsoni sp. nov.}

(Figures 7-12)

http://www.zoobank.org/ urn:Isid:zoobank. org:act:DFA82FDC-8C2B-44D1-8B16-7765E75D96CB

\section{MATERIAL EXAMINED}

\section{Holotype}

Australia: Western Australia: female, Pilbara region, Fortescue River catchment, bore HPRC4121, $22^{\circ} 09^{\prime} 23.1^{\prime \prime} \mathrm{S} 117^{\circ} 26^{\prime} 22.5^{\prime \prime} \mathrm{E}$, G. Pearson and S. Bennett, 21 August 2011 (WAM C55893, dissected on slide). Depth to watertable $26 \mathrm{~m}$, temperature $27.8^{\circ} \mathrm{C}$, pH 6.74, electrical conductivity $879 \mathrm{~S} / \mathrm{cm}$ (Table 1).

\section{Allotype}

Australia: Western Australia: male, Pilbara region, Fortescue River catchment, bore HPRC4121, $22^{\circ} 09^{\prime} 23.1^{\prime \prime} \mathrm{S} 117^{\circ} 26^{\prime} 22.5^{\prime \prime} \mathrm{E}$, G. Pearson and S. Bennett, 21 August 2011 (WAM C55894, dissected on slide).

\section{Paratypes}

Australia: Western Australia: Pilbara region, Fortescue River catchment, bore HPRC4121, $22^{\circ} 09^{\prime} 23.1^{\prime \prime} \mathrm{S} 117^{\circ} 26^{\prime} 22.5^{\prime \prime} \mathrm{E}, \mathrm{G}$. Pearson and S. Bennett, 21 August 2011, female (WAM C55895, dissected on slide); female (WAM C55896, dissected on slide); male (WAM C55897, dissected on slide); 1 female in alcohol (WAM C55898); 1 male in alcohol (WAM C55899); 1 male in alcohol (WAM C55900); 4 males, 7 females in alcohol (WAM C60014); 2 males and 5 females (WAM C55892) on one SEM stub; J. Cocking \& J. Quartermaine, 26 July 2011, 1 male and 3 females in alcohol (WAM C55902).

\section{Other material}

Australia: Western Australia: Pilbara region, Fortescue River catchment, bore HPRC0096, $22^{\circ} 09^{\prime} 23.0^{\prime \prime S} 117^{\circ} 27^{\prime} 24.0^{\prime \prime} \mathrm{E} ;$ D. Main \& J. Quartermaine, 15 April 2011, male in alcohol (WAM C55903); bore HPRC4254, 22 $10^{\prime} 30.3^{\prime \prime} \mathrm{S}$ $117^{\circ} 29^{\prime} 19.5^{\prime \prime} \mathrm{E}$; M. Curran \& J. Cocking, 16 April 2011, 5 males and 3 females in alcohol (WAM C55904); bore HPRC0379, 22 $08^{\prime} 07.2^{\prime \prime} \mathrm{S} 117^{\circ} 25^{\prime} 55.7^{\prime \prime} \mathrm{E}$; J. Cocking \& J. Quartermaine, 31 July 2011, 1 female and 2 males in alcohol (WAM C55905); bore HPRC4119, 2209'29.0"S $117^{\circ} 26^{\prime} 18.8^{\prime \prime} \mathrm{E}$; G. Pearson \& S. Bennett, 21 August 2011, 2 males in alcohol (WAM C55906); bore HPRC0504, $22^{\circ} 06^{\prime} 52.8^{\prime \prime} \mathrm{S} 117^{\circ} 26^{\prime} 31.8^{\prime \prime E}$; G. Pearson \& S. Bennett, 19 August 2011,4 males and 1 female in alcohol (WAM C55907); 1 female dissected on slide (WAM C57231).

\section{DIAGNOSIS}

Anzcyclops pearsoni sp. nov. differs from previously described species of Anzcyclops, other than A. trotteri sp. nov., by having pronounced ornamentation of the somites (all other described species have smooth somites), a large spine-like posterolateral projection of 
the dorsal side of the genital double-somite, a triangular operculum (other species have a rounded operculum), the lack of an apical spine on the second endopodal segment of fourth swimming leg (a secondary apical seta is present but other species have an apical spine instead, except for A. belli Karanovic, Eberhard \& Murdoch, 2011 and A. trotter sp. nov.). A. pearsoni sp. nov. is distinguished from $A$. trotteri sp. nov. by possessing a simple $\mathrm{W}$-shaped projection in the medial dorsal hyaline fringe of the genital double-somite of both sexes and by smoother scalloping of the dorsal hyaline fringe of posterior urosomites.

\section{DESCRIPTION}

\section{Female}

Total body length from tip of rostrum to end of the caudal rami ranges from 279-350 m (mean $302 \mathrm{~m}$ $\mathrm{n}=9$ ). Body robust, wide, strongly dorsoventrally compressed (Figures 7A, B, 11A, G), with prosome/ urosome ratio 1.9 and greatest width at posterior end of cephalothorax. Body length/width ratio approximately 2.0 (dorsal view); cephalothorax 1.5 times as wide as genital double-somite. Free pedigerous somites with slight lateral expansions but an overall outline typical of the genus. Nauplius eye visible. Rostrum large, broadly rounded, and furnished with 2 large sensilla. Cephalothorax large, as long as wide (dorsal view); representing approximately $40 \%$ of total body length (Figure 11A). Surface of cephalothoracic shield and pleurotergites of free pedigerous somites ornamented with several sensilla and with irregular reticulum of pits; integumental reticular pattern present as in other described species of Anzcyclops on all somites, but absent from all appendages (Figure 11C). Hyaline fringes of prosomites narrow and smooth. Fifth pedigerous somite ornamented with 2 dorsal ( 1 on each side) large sensilla; lateral edges produced into recurved spine dorsally, hyaline fringe smooth on all sides (Figures 7C, D, 11D).

Genital double-somite large, with expanded anterior part and deep lateral recesses at level of the sixth legs, 1.9 times as wide as long (dorsal view), ornamented with pits but without sensilla; hyaline fringe of genital double-somite with median W-shaped lobe dorsally (Figures 7C, D, 11D). Copulatory pore ovoid, situated at $1 / 3$ of somite length; copulatory duct narrow, siphonshaped, well sclerotised. Seminal receptacle with small anterior expansion and larger posterior expansion, representing $71 \%$ of double-somite's length; oviducts broad and strongly sclerotised. Ovipores situated dorsolaterally.

Third and fourth urosomites without any pores or sensilla, ornamented only with cuticular pits; hyaline fringe scalloped dorsally, ventrally smooth (Figures 7C, $\mathrm{D}, 11 \mathrm{~F})$. Third urosomite 1.2 times as long as fourth.

Anal somite ornamented with 2 large sensilla dorsally and transverse row of spinules along posterior margin ventrally and laterally (Figures 7C, D). Anal sinus smooth and completely covered by very large triangular anal operculum (Figure $11 \mathrm{~F}$ ), produced posteriorly well beyond somite margin to about $1 / 2$ of the length of the caudal rami and representing $50 \%$ of anal somite width.

Caudal rami (Figures 7C, D, 11F) cylindrical, almost parallel, closely inserted (with space between them about $1 / 5$ of ramus width) and about 1.6 times as long as wide; ornamented with several spinules at base of 2 lateral setae. Dorsal seta strong, about 1.3 times as long as ramus, inserted at $3 / 4$ of ramus length, biarticulate at base and plumose. Anterolateral seta arising somewhat dorsolaterally at middle of ramus length, 0.5 times as long as dorsal seta. Posterolateral seta stout, spiniform and bipinnate, about as long as ramus. Terminal accessory seta also bipinnate, 0.6 times as long as posterolateral seta but not as strong. Terminal setae with breaking planes, bipinnate. Inner terminal seta about 1.5 times as long as outer 1 and half as long as body length.

Antennule (Figure 9A) 11-segmented, reaching $3 / 4$ of cephalothoracic shield in length, unornamented. Armature formula as follows: 5.1.5.2.1.2.3.2+ae.2.2.7+ae. No setae biarticulating on basal part, 2 setae on the eighth segment pinnate, all other setae smooth. Both aesthetascs slender, apical aesthetasc as long as terminal 3 segments combined. Length ratio of segments: $1: 0.5: 0.6: 0.3: 0.3: 0.4: 1$ $: 0.8: 0.5: 0.8: 1$.

Antenna (Figure 9E) 4-segmented, comprising coxobasis and 3-segmented endopod. Coxobasis large, cylindrical, twice as long as wide, unornamented, armed with 2 smooth distomedial setae; seta representing exopod absent; original segmentation of coxa marked by partial transverse surface suture. First endopodal segment 1.3 times as long as wide, with inner smooth seta at $2 / 3$ and patch of spinules along lateral margin. Second endopodal segment more slender, about 1.7 times as long as wide, with distal part bearing 6 medial setae ( 2 sub-distal) and 1 spinular row on lateral margin. Third endopodal segment cylindrical, twice as long as wide, with 2 spinular rows on lateral margin and armed with 7 smooth apical setae (3 of them strong and geniculate). Length ratio of antennal segments from proximal end: $1: 0.7: 0.6: 0.7$.

Labrum, not figured, small trapezoidal plate, ornamented with 2 diagonal, short rows of long spinules on anterior surface. Cutting edge slightly concave, with 14 large and sharp teeth between produced rounded lateral corners. 


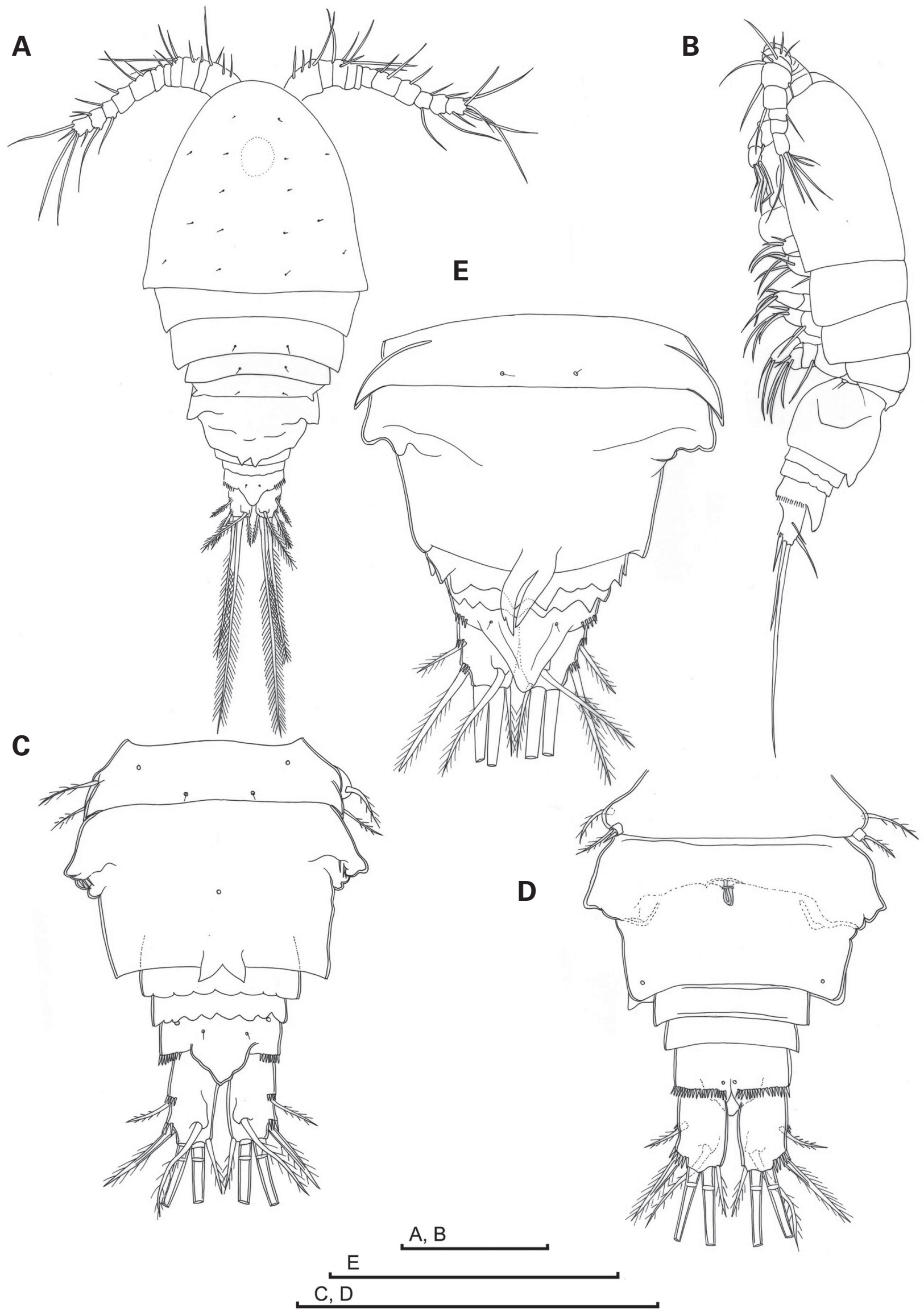

FIGURE 7 Anzcyclops pearsoni sp. nov. A, habitus, dorsal, paratype, female (WAM C55898); B, habitus, lateral, paratype, female 1; C, urosome, dorsal, holotype female 4; D, urosome, holotype female; E, urosome, dorsal, animal variant (WAM C57231). Scale bar $0.1 \mathrm{~mm}$. 
A B
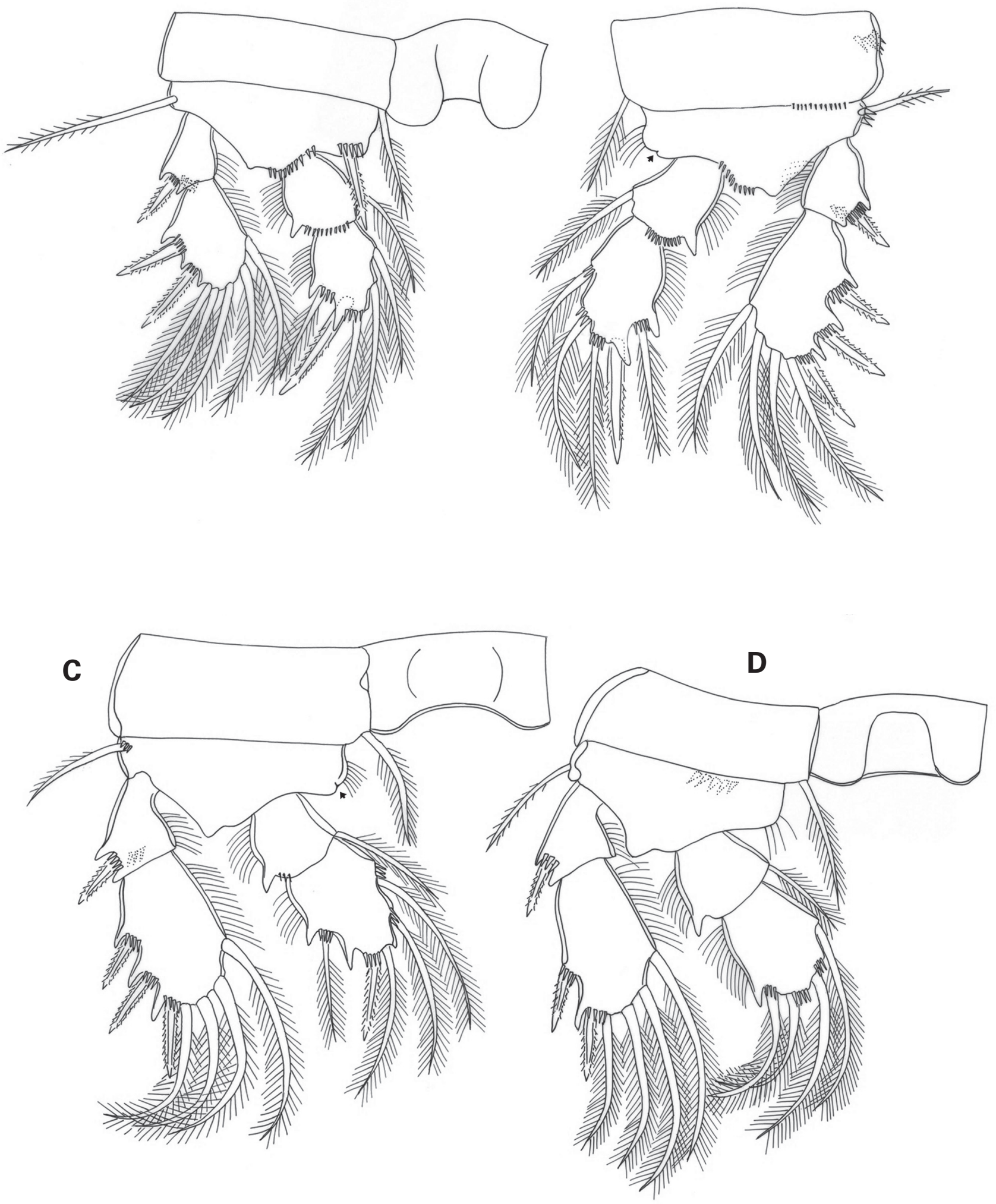

FIGURE 8 Anzcyclops pearsonisp. nov. A, B holotype female; C, D paratype female (WAM C55900). A, first swimming leg, anterior; B, second swimming leg, anterior; C, third swimming leg, anterior; D, fourth swimming leg, anterior. Scale bar $0.1 \mathrm{~mm}$. 


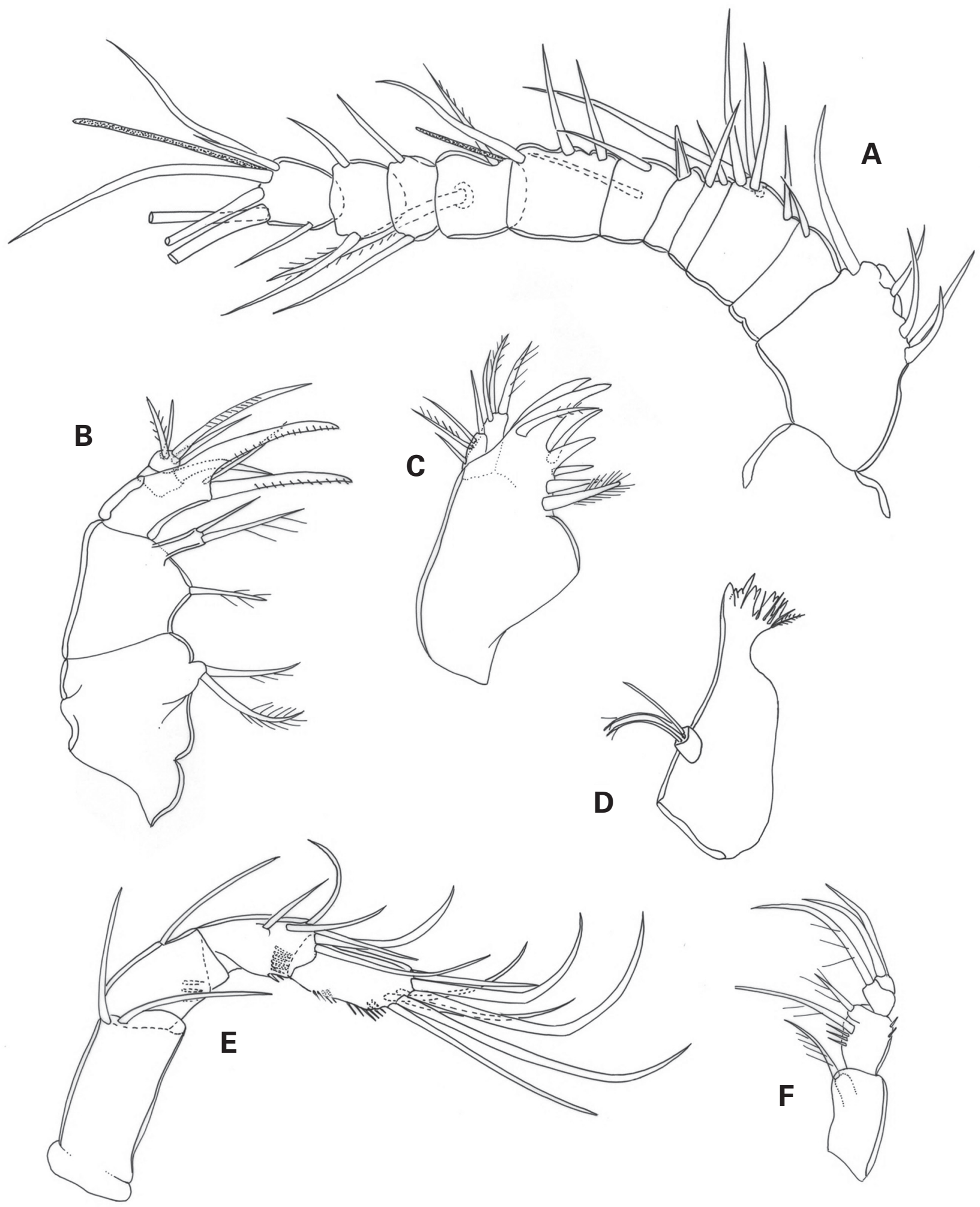

FIGURE 9 Anzcyclops pearsonisp. nov. B, C, E, F paratype female 3. A, antennula, dorsal, holotype animal; B, maxilla, posterior; C, maxillula, posterior; D, mandibula, posterior paratype female (WAM C55895); E, antenna, caudal; F, maxilliped, posterior. 


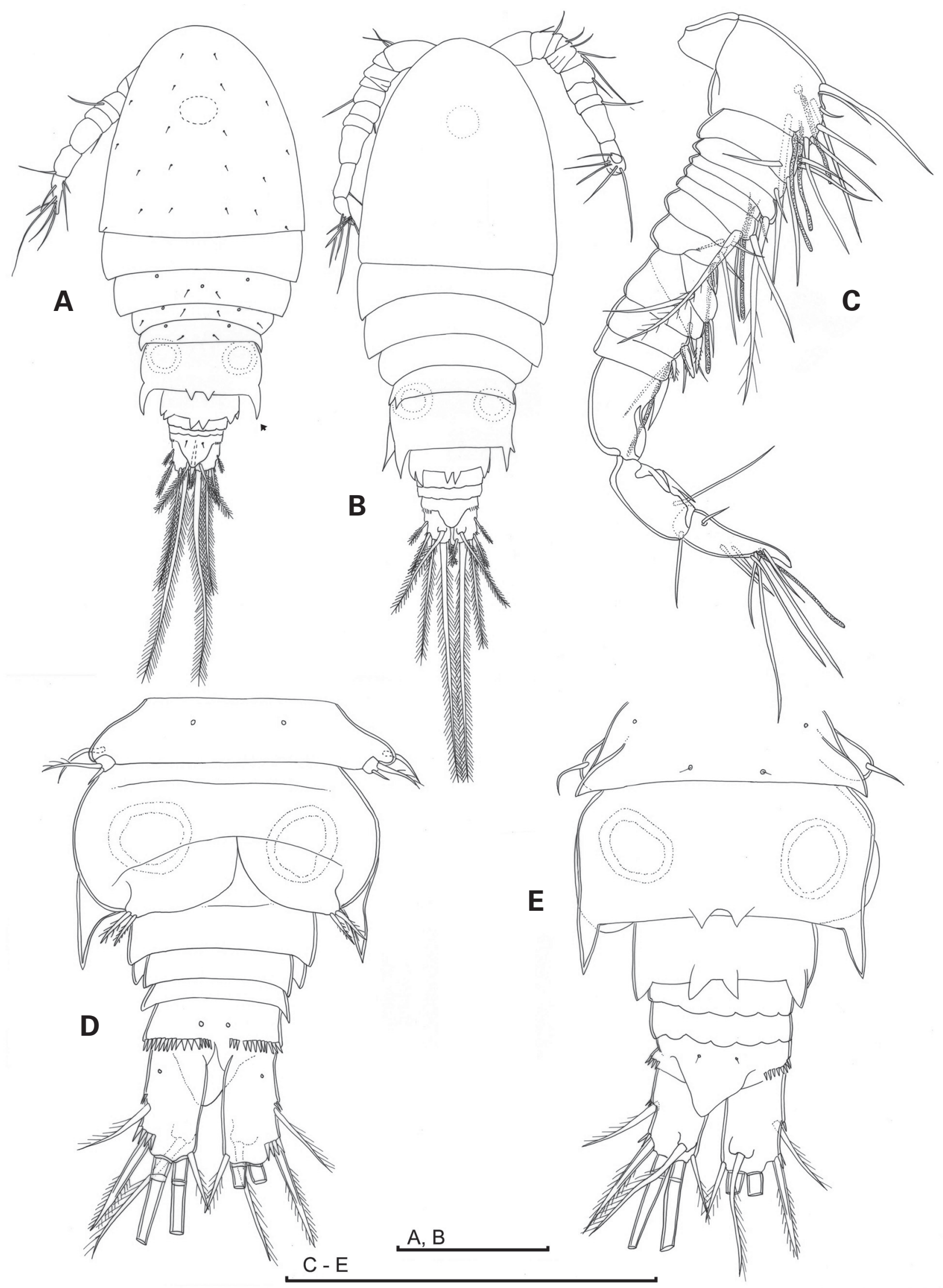

FIGURE 10 Anzcyclops pearsoni sp. nov. C, D, E allotype male. A, habitus, dorsal paratype male (WAM C55896); B, habitus, dorsal, paratype male (WAM C55899); C, antennula, ventral; D, urosome, ventral; E, urosome, dorsal. 

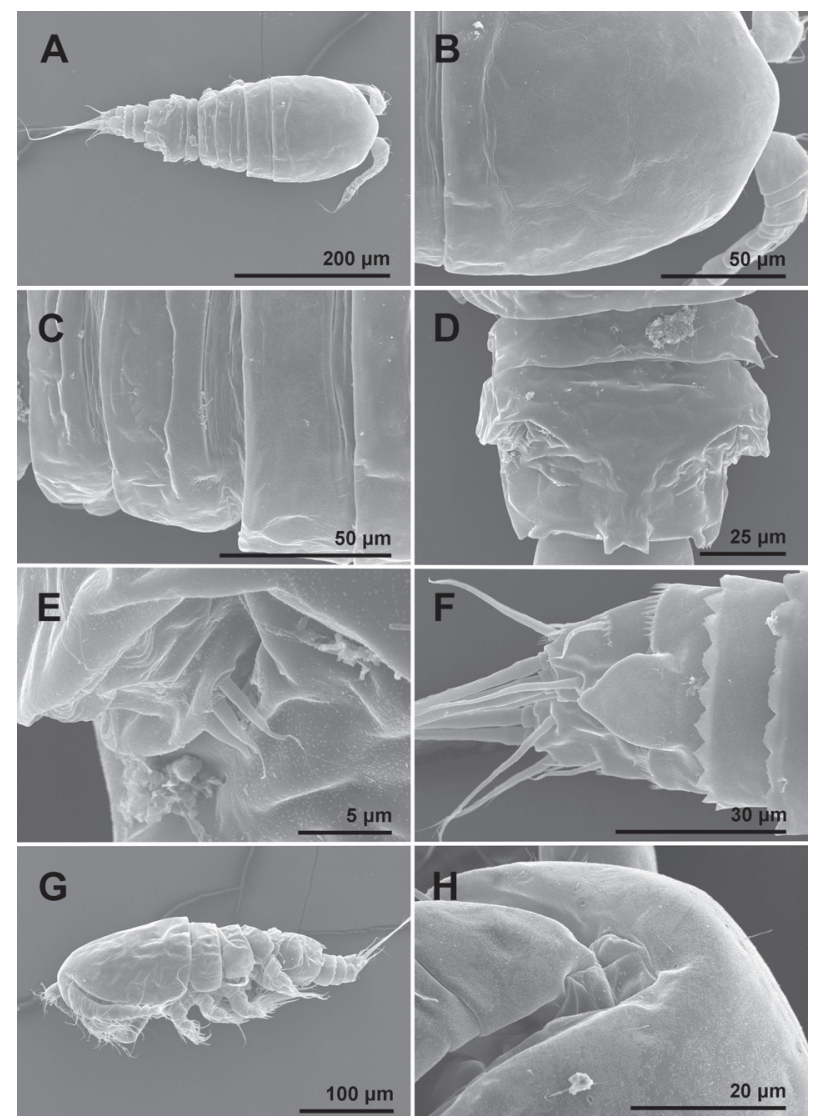

FIGURE 11 Anzcyclops pearsoni sp. nov. SEM micrographs (WAM C55892), A-F paratype female 1, G, H, paratype female 2: $A$, habitus, dorsal; B, cephalothorax, dorsal; C, tergites of free pedigerous somites, dorsal; D, fifth pedigerous somite and genital double-somite, dorsal; E, sixth leg, dorsal; $F$, last three urosomites and caudal rami, dorsal; $\mathrm{G}$, habitus, lateral; $\mathrm{H}$, rostrum and first antennular segment, lateral.

Mandible (Figure 9D) composed of coxa and small palp. Coxal gnathobase cutting edge with 3 spinules on anterior surface and 4 apical teeth (ventral most tooth strongest and complex, quadridentate; second and third tooth bidentatae), and 2 setae on dorsal corner. Palp, unornamented but armed with 3apical setae: 2 long and 1 short and smooth.

Maxillule (Figure 9C) composed of praecoxa and 2 segmented palp. Praecoxal arthrite bearing 3 very strong distal spines, smooth, blunt, and fused at base, plus 1 sharp, and 1 spinulate setae; and 3medial elements (proximal longest and plumose, others smooth). Palp composed of coxobasis and endopod. Coxobasis with smooth proximal (exopodal) seta and 3 medial setae (1 smooth and slender, 2 bipinnate); endopod with 1 smooth and 2 pinnate setae.

Maxilla (Figure 9B) 5-segmented, but praecoxa partly
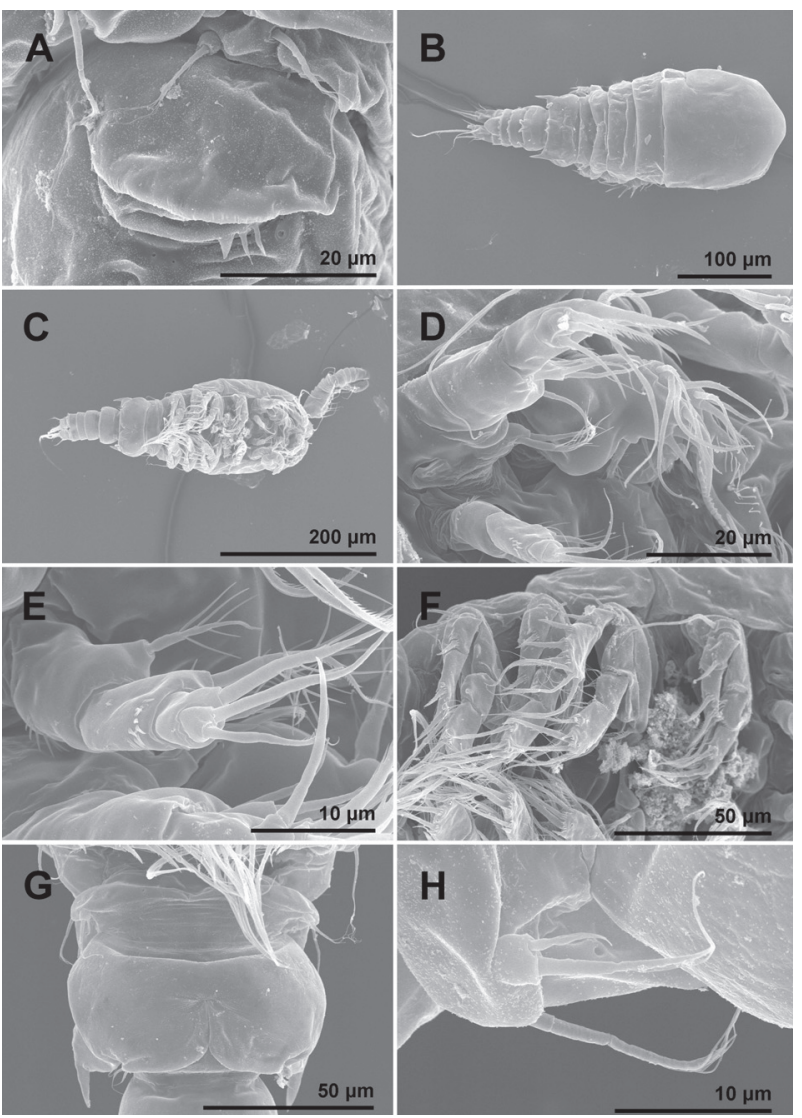

FIGURE 12 Anzcyclops pearsoni sp. nov. SEM micrographs (WAM C55892), C-H paratype male 2. A, fifth and sixth legs, lateral, paratype female (WAM C55000); B, habitus, dorsal, paratype male (WAM C55000); C, habitus, ventral; $D$, maxillula and maxilla, ventral; E, maxilliped, ventral; F, swimming legs, ventral; G, first two urosomites, ventral; $\mathrm{H}$, fifth leg, ventral.

fused to coxa on posterior surface. Endite of praecoxa robust, armed with 2 subequal, pinnate setae. Proximal endite of coxa reduced to a knob with 1 bipinnate seta; distal endite highly mobile, elongate, and armed apically with 2 setae, 1 of which is pinnate; coxa unornamented. Basis expanded into robust claw, ornamented with 2 longitudinal rows of spinules, and armed with 1 seta and a second seta transformed into a large claw. Endopod 2-segmented; proximal segment armed with 1 robust, unipinnate setae; distal segment with 1 robust, unipinnate, apical seta, 2 slender and smooth subapical setae and 1 bipinnate setae. All strong setae, as well as basal claw, prehensile.

Maxilliped (Figure 9F) 4-segmented, composed of syncoxa, basis, and 2 segmented endopod. Ornamentation consisting of several longitudinal rows of spinules on basis. Syncoxa appears to be armed with only 1 strong seta. Armature formula: 1.2.1.2. 
Inner spine on basis of first swimming leg short, reaching slightly beyond distal margin of first endopodal segment (Figure 8A). Outer seta on basis of first swimming leg very long and bipinnate; those on other legs shorter. Inner distal corners of basis of second and third legs notched (arrowed in Figures 8B, C). Basis of fourth swimming leg with round inner distal corners, ornamented with long setules. Intercoxal sclerites of all swimming legs with concave distal margins and without any surface ornamentation. Praecoxae short and unornamented. Coxa of first swimming leg unornamented, coxa of second swimming leg ornamented with short distal row of minute spinules on anterior margin; and a larger spinule patch on posterior surface close to outer margin.

All swimming legs with sub-equal 2-segmented exopods and endopods (Figures 8A-D). Second exopodal segment spine formula 2.3.3.2 and setal formula 5.4.4.4. The complete armature formula is:

$\begin{array}{lllll} & \text { Coxa } & \text { Basis } & \text { Exopod } & \text { Endopod } \\ \text { Leg 1 } & 0-1 & 1-\mathrm{I} & \mathrm{I}-0 ; \mathrm{I}, \mathrm{I}+1,4 & 0-1 ; 1, \mathrm{I}+1,2 \\ \text { Leg 2 } & 0-1 & 1-0 & \mathrm{I}-0 ; \mathrm{II}, \mathrm{I}+1,3 & 0-1 ; 1, \mathrm{I}+1,2 \\ \text { Leg 3 } & 0-1 & 1-0 & \mathrm{I}-0 ; \mathrm{II}, \mathrm{I}+1,3 & 0-1 ; 1, \mathrm{I}+1,2 \\ \text { Leg 4 } & 0-1 & 1-0 & \mathrm{I}-0 ; \mathrm{I}, \mathrm{I}+1,3 & 0-1 ; 1,1,2\end{array}$

All setae on endopods and exopods slender and plumose; all spines strong and bipinnate.

Long setules on inner margin of exopods and outer margin of endopods; both rami additionally ornamented with minute spinules at base of each armature element and the base of each segment except fourth leg. Second (Figure 8B) and third (Figure 8C) swimming legs very similar, except apical spine on second leg endopod somewhat larger. Endopod of fourth swimming leg (Figure 8D) as wide as exopod but slightly shorter; second endopodal segment about as long as wide and without apical spine.

Fifth leg (Figures 7D, 12A) held ventrolaterally, composed of protopod completely fused to somite and free exopod. Protopodal seta small and slender but visible in dorsal view, without prominent setophore, smooth. Exopod quadriform and very small, about as long as wide, armed apically with outer bipinnate seta and inner smooth spine; seta about 3 times as long as adjacent spine.

Sixth leg (Figures 11E, 12A) small, semicircular cuticular plate, armed with 3 short spines; inner spine thick, fused to plate, outer spines articulated.

\section{Male}

Total body length ranges from 268-331 m (mean $288 \mathrm{~m} ; \mathrm{n}=9$ ). Body (Figures 10A, 12B, C) much more slender than in female, prosome/urosome ratio about 1.9 and greatest width at posterior end of cephalothorax. Body length/width ratio 2.2; cephalothorax about 1.7 times as wide as genital somite. Cephalothorax about as long as wide (dorsal view), representing $47 \%$ of total body length. Ornamentation of prosomites similar to female. Hyaline fringe of fifth pedigerous somite (Figures 10D, E) smooth ventrally and dorsally; somite ornamented as in female but lateral edges produced into larger recurved spines (arrowed in Figure 10A).

Genital somite (Figures 10D, E, 12G) more than twice as wide as long, hyaline fringe with median $\mathrm{W}$-shaped lobe dorsally as in the female; posterolateral edges produced into a large caudally directed spine-like lobe; 2 ovoid spermatophores visible inside.

Third urosomite with hyaline fringe smooth ventrally; dorsally with large median $\mathrm{W}$-shaped lobe, 2 times longer than lobe on genital somite; anterior-lateral edges produced into a small posteriorly directed spine like lobe, about $1 / 3$ of size of lobe on genital somite (Figure $10 \mathrm{E})$; next 2 urosomites without any ornamentation; all urosomites with hyaline fringes dorsally scalloped and ventrally smooth.

Anal somite ornamented as in female but anal operculum (Figure 10E) larger, reaching 2/3 length of caudal rami. Caudal rami (Figure 10D, E) with ornamentation, as well as armature and proportions same as in female.

Antennule (Figures 10C, 12H) digeniculate, 15-segmented, with spine-shaped cuticular structures on thirteenth and fourteenth elements (distal geniculation). Armature formula: $8+3 \mathrm{ae} \cdot 4 \cdot 1.2+$ ae.1.2.2.3 + ae.2.2.2.2 + ae.0.1.9+ ae.

Antenna, labrum, mandible, maxillule, maxilla, maxilliped, swimming legs, and fifth leg similar to those of female. Sixth leg (Figure 10D) large, unornamented cuticular plate, armed with inner spine and outer seta on outer distal corner; both bipinnate and seta just longer than spine.

\section{ETYMOLOGY}

The species is named after Grant Pearson, formerly of the Department of Parks and Wildlife and then Bennelongia Environmental Consultants, in recognition of his valuable work collecting subterranean fauna, including the type material of this species, across Western Australia.

\section{VARIABILITY}

The cuticular ornamentation is very variable and may be more or less visible due to the preservation of the specimen. The $\mathrm{W}$-shaped lobe on the genital doublesomite is variable in shape and the scalloping on the hyaline fringe of urosomites is also variable. The dorso- 
lateral edges of the fifth pedigerous somite are variously produced and are more rounded in some specimens. The operculum may vary in size.

One male paratype (Figure 10B) shows many variations in morphology with the genital double-somite lacking a median $\mathrm{W}$-shaped lobe dorsally and having two asymmetrical posteriorly directed spine like lobes. The anterior-lateral edges of the third urosomite are produced into two small posteriorly directed spine like lobes. The two female specimens collected from drill hole HPRC0504 have an extremely elongated median lobe on the genital double-somite, larger operculum, more serrated hyaline fringe on dorsal urosomites and the dorsolateral edges of fifth pedigerous somite are markedly produced and recurved (Figure 7E); the four males from this site have the normal form of the $\mathrm{W}$-shaped lobe on the third urosomite but the W-shaped lobe is absent from the genital double-somite. This population may be a different species.

\section{DISCUSSION}

\section{Distributions}

The eight known species of Anzcyclops are amongst the smallest known cyclopoid copepods. All seven described species have total lengths (excluding caudal setae) $<0.5 \mathrm{~mm}$, with most species being about $0.3 \mathrm{~mm}$ long. Six of the species occur in Australia, one is found in New Zealand, while an eighth species from India is currently being described. Five of the Australian species are known only from the Pilbara region.

Three of the Pilbara species (A. belli Karanovic, Eberhard \& Murdoch, 2011, A. trotteri sp. nov., A. yarriensis Karanovic, Eberhard \& Murdoch, 2011) are known from single sites, despite sampling being quite intensive in the local areas where they were collected. Anzcyclops ballensis Karanovic, Eberhard \& Murdoch, 2011 is known from three sites within a distance of $5 \mathrm{~km}$ and A. pearsoni sp. nov. from six sites within a distance of $8 \mathrm{~km}$ (Figure 1). Each species occurs within a different river catchment (A. trotteri in the Robe, $A$ pearsoni in the Fortescue). The small ranges of both species suggest that Anzcyclops species in the Pilbara are most definitely short range endemics as defined by either Harvey's (2002) criterion of range $<10,000 \mathrm{~km} 2$ or Eberhard et al.'s (2009) tighter criterion of range $<1000 \mathrm{~km}^{2}$.

Despite being in different catchments, the known ranges of both new species lie in the Fortescue River basin and, not surprisingly, these two species have the greatest number of shared morphological characters of all Anzcyclops species. The known range of $A$. belli is just north of the Fortescue River basin and it is the species geographically closest to $A$. trotteri sp. nov. and A. pearsoni sp. nov. Anzcyclops belli shares a significant number of morphological characters with $A$. trotteri sp. nov. and A. pearsoni sp. nov. (see below).

The richness of Anzcyclops species in the Pilbara and their small ranges reflect the importance of the Pilbara region for subterranean fauna (Halse et al. 2014; Halse and Pearson 2014) and the high levels of endemism present in its copepod fauna (Karanovic 2006; Karanovic et al. 2011). However, it should be recognised that while the Pilbara and adjacent Yilgarn regions in Western Australia appear to support substantially richer stygofauna communities than other parts of Australia (Guzik et al. 2010), there has been comparatively little study of stygobitic copepods elsewhere in Australia and the number of described species in Queensland and New South Wales considerably underestimates known stygobitic copepod biodiversity in those states (e.g. Hancock and Boulton 2008; Karanovic and Hancock 2009).

\section{Ecology}

Studies of copepods in Australian groundwater are still in their infancy, with the primary focus being identifying new species and unravelling species complexes (e.g. Karanovic and Cooper 2011, 2012). There has been little study of the ecology and life history of different species. The limited information available suggests that four of the Pilbara species (no information is available for A. ballensis from the coastal part of the Sherlock River catchment) and the Queensland species occur in fresh groundwater of neutral to slightly acidic $\mathrm{pH}$ (Table 1). Known depths to groundwater vary from 5 to $40 \mathrm{~m}$. Of the species in the Pilbara, A. ballensis, A. belli and A. yarriensis have been collected in groundwater in fractured rock basalts (Karanovic et al. 2011), which Halse et al. (2014) identified as a geology likely to yield stygofauna. Anzcyclops pearsoni sp. nov. and A. trotteri sp. nov. were collected from areas containing alluvial and channel iron deposit aquifers (Table 1). Alluvium is widely recognised as an important habitat for stygofauna (e.g. Hahn and Matzke 2005; Halse et al. 2014) but $A$. trotteri sp. nov. and $A$. pearsoni sp. nov. appear to utilise detrital and channel iron deposits as well.

\section{Taxonomy}

The two new species, Anzcyclops pearsoni sp. nov. and $A$. trotteri sp. nov., share the same armature formula of the swimming legs, pronounced spiniform processes on the urosomites, very long and triangular anal operculum, and similar shape and armature of the caudal rami. Their known distributions are also in the same broad drainage basin (Fortescue, see above) and it appears likely they originated from a common recent ancestor. They can be chiefly distinguished by the subtle differences in body shape, number and size of spiniform processes on urosomites, and segmentation of the antennule. The latter character is probably of little phylogenetic significance. Anzcyclops ballensis shares the characteristic of a 10 -segmented antennule with $A$. 
trotteri sp. nov, although it shares few other characters (others than those that are diagnostic of the genus) with either $A$. trotteri sp. nov. or A. pearsoni sp. nov.

The 10-segmented state of the antennule recorded in $A$. ballensis and $A$, trotteri sp. nov. may be the result of convergence, even though in both cases the reduction in segmentation is a consequence of absence of articulation between the ancestral second and third segments. Differences between A. ballensis and the two new species include, but are not limited to: body shape (not dorsoventrally compressed in A. ballensis), lateral protrusions of the genital double-somite (absent in $A$. ballensis), sculpturing of the hyaline membrane on urosomites (finely serrated in A. ballensis), shape and length of the anal operculum (shorter and linguiform in $A$. ballensis), length of the caudal rami (longer in A. ballensis), proportions of armature elements on the caudal rami (innermost apical setae longer than outermost apical setae in $A$. ballensis), armature of the mandible (only two setae in $A$. ballensis), armature of the maxilliped (no setae on the first segment in $A$. ballensis), and armature of the fourth leg endopod (apical spine present and outer seta absent in $A$. ballensis).

The new species share the greatest number of morphological characters with $A$. belli, which also is closest to them geographically (see above). These three species all have a similar body shape, pronounced lateral protrusions on the genital double-somite, long anal operculum, caudal ramus of similar proportions with the innermost apical seta significantly shorter than the outermost, very similar shape and armature of cephalic appendages, exactly the same armature formula of all swimming legs, and a similar fifth leg. Females of $A$. belli differ from females of the two new species by absence of pronounced spiniform processes on urosomites (although the hyaline in A. belli is very roughly serrated), linguiform shape of the anal operculum, and in having longer dorsal setae on the caudal rami. Unfortunately, the males of $A$. belli are as yet unknown, so the male characters could not be compared.

Excluding A. belli, A. trotteri sp. nov. and A. pearsoni sp. nov. from the central Pilbara, the remaining four species of the genus Anzcyclops appear to form a rather heterogeneous group. The occurrence of Anzcyclops species in the highly disjunct areas of Western Australia, Queensland, New Zealand and India suggests the possibility of a long evolutionary history. As the survey of subterranean diversity in Australia and Asia is still in its infancy, it is expected that more species of Anzcyclops will be discovered and that these species may provide missing links between the currently known species of Anzcyclops.

A key to the described species of Anzcyclops, based on female characters, is provided below.

\section{KEYTO SPECIES OF ANZCYCLOPS}

(see Karanovic et al. 2011)

1. Endopod segment 2 of fourth leg with outer seta 3

Endopod segment 2 of fourth leg lacking outer seta ......................................................................... 2

2. Body shape dorsoventrally depressed..... A. silvestris (Harding, 1958)

Body shape of typical cyclopiform pattern A. ballensis Karanovic, Eberhard \& Murdoch, 2011

3. Endopod segment 2 of fourth leg with apical spine

Endopod segment 2 of fourth leg without apical spine .

4. Endopod of fourth leg with 3 inner setae on second segment

A. yarriensis Karanovic, Eberhard \& Murdoch, 2011

Endopod of fourth leg with 2 inner setae on second segment.

A. euryantennula Karanovic, Eberhard \& Murdoch, 2011

5. Dorsal hyaline fringe of genital double-somite with W-shaped medial lobe; anal operculum triangular

Dorsal hyaline fringe of genital double-somite without medial lobe; anal operculum linguiform. .... A. belli Karanovic, Eberhard \& Murdoch, 2011

6. Dorsal hyaline fringe of genital double-somite with simple W-shaped medial lobe; dorsal hyaline fringe of third and fourth urosomites with moderately smooth scalloping.

A. pearsoni sp. nov.

Dorsal hyaline fringe of genital double-somite with serrated W- shaped; third and fourth urosomites with strong irregular serrations

A. trotteri sp. nov.

\section{ACKNOWLEDGMENTS}

We would like to thank staff of Bennelongia Environmental Sciences (Sean Bennett, Jim Cocking, Michael Curran, Dean Main, Grant Pearson and Jeremey Quartermaine) for collecting the material on which this paper is based. Mike Scanlon prepared Figure 1. Scanning electron microscopy was made available through Prof. Jin Hyun Jun (Eulji University, Seoul), and we also want to thank Mr Junho Kim (Eulji University, Seoul) for the technical help provided. Prof. Yenumula Ranga Reddy (Acharya Nagarjuna University, Nagarjunanagar) kindly shared with us information from his unpublished manuscript. Finally, we thank two anonymous reviewers for their detailed comments on the manuscript. 


\section{REFERENCES}

Eberhard, S.M., Halse, S.A., Scanlon, M.D., Cocking, J.S. and Barron, H.J. (2005). Assessment and conservation of aquatic life in the subsurface of the Pilbara region, Western Australia (pp 61-68). In: Gibert, J. (ed.), World Subterranean Biodiversity. Proceedings of an International Symposium, 8th - 10th December 2004, Villeurbanne, France. University Claude Bernard of Lyon 1, PASCALIS European Research Programme, Lyon.

Eberhard, S.M., Halse, S.A., Williams, M.R., Scanlon, M.D., Cocking, J.S. and Barron, H.J. (2009). Exploring the relationship between sampling efficiency and short range endemism for groundwater fauna in the Pilbara region, Western Australia. Freshwater Biology 54: 885-901.

Guzik, M.T., Austin, A.D., Cooper, S.J.B., Harvey, M.S., Humphreys, W.F., Bradford, T., Eberhard, S.M., King, R.A., Leys, R., Muirhead, K.A. and Tomlinson, M. (2010). Is the Australian subterranean fauna uniquely diverse? Invertebrate Systematics 24: 407-418.

Hahn, H.J. and Matzke, D. (2005). A comparison of stygofauna communities inside and outside groundwater bores. Limnologica 35: 31-44.

Halse, S.A. and Pearson, G.B. (2014). Troglofauna in the vadose zone: comparison of scraping and trapping results and sampling adequacy. Subterranean Biology 13: 17-34.

Halse, S.A., Scanlon, M.D., Cocking, J.S., H.J., B., Richardson, J.B. and Eberhard, S.M. (2014). Pilbara stygofauna: deep groundwater of an arid landscape contains globally significant radiation of biodiversity. Records of the Western Australian Museum, Supplement 78: 443-483.

Hancock, P.J. and Boulton, A.J. (2008). Stygofauna biodiversity and endemism in four alluvial aquifers in eastern Australia. Invertebrate Systematics 22: 117-126.

Harvey, M. (2002). Short-range endemism among the Australian fauna: some examples from non-marine environments. Invertebrate Systematics 16: 555-570.

Huys, R., and Boxshall, G.A. (1991). Copepod Evolution. Ray Society, London.

Johnson, S.L. and Wright, A.H. (2001). Central Pilbara groundwater study, Western Australia. HG8, Water and Rivers Commission, Perth.

Karanovic, I. (2007). Candoninae (Ostracoda) from the Pilbara region in Western Australia. Crustaceana Monographs 7: $1-432$.

Karanovic, I. and McKay, K. (2010). Two new species of Leicacandona Karanovic (Ostracoda, Candoninae) from the Great Sandy Desert, Australia. Journal of Natural History 44: $2715-2736$.

Karanovic, T. (2006). Subterranean copepods (Crustacea, Copepoda) from the Pilbara region in Western Australia. Records of the Western Australian Museum, Supplement 70: $1-239$.
Karanovic, T. (2010). First record of the harpacticoid genus Nitocrellopsis (Copepoda, Ameiridae) in Australia, with descriptions of three new species. Annales de Limnologie 46: $249-280$.

Karanovic, T. and Cooper, S.J.B. (2011). Molecular and morphological evidence for short range endemism in the Kinnecaris solitaria complex (Copepoda: Parastenocarididae), with descriptions of seven new species. Zootaxa 3026: 1-64.

Karanovic, T., and Cooper, S.J.B. (2012) Explosive radiation of the genus Schizopera on a small subterranean island in Western Australia (Copepoda: Harpacticoida): unravelling the cases of cryptic speciation, size differentiation and multiple invasions. Invertebrate Systematics 26: 115-192.

Karanovic, T., Eberhard, S.M. and Murdoch, A. (2011). A cladistic analysis and taxonomic revision of Australian Metacyclops and Goniocyclops, with description of four new species and three new genera (Copepoda, Cyclopoida). Crustaceana 84: 1-67.

Karanovic, T. and Hancock, P. (2009). On the diagnostic characters of the genus Stygonitocrella (Copepoda, Harpacticoida), with descriptions of seven new species from Australian subterranean waters. Zootaxa 2324: 1-85.

Karanovic, T. and Krajicek, M. (2012). First molecular data on the Western Australian Diacyclops (Copepoda, Cyclopoida) confirm morpho-species but question size differentiation and monophyly of the alticola-group. Crustaceana 85:15491569.

Karanovic, T. and McRae, J. (2013). The genus Schizopera (Copepoda, Harpacticoida) in the Pilbara region of Western Australia, with description of a new species and its molecular and morphological affinities. Records of the Western Australia Museum 28: 119-140.

Sheppard, G., Gallardo, A., Hall, J. and Strizek, M. (2009). Managing the cumulative groundwater impacts of multiple iron ore projects at Cape Preston (or ... one plus one plus one plus one does not equal four). Mining Technology 118: $152-161$.

Stock, J.H., and Von Vaupel Klein, J.C. (1996). Mounting media revisited: the suitability of Reyne's fluid for small crustaceans. Crustaceana 69: 794-798.

Tang, D., Barron, H. and Goater, S.E. (2008). A new genus and species of the Ridgewayiidae (Copepoda: Calanoida) from subterranean waters of northwestern Australia. Journal of Crustacean Biology 28: 551-563.

Totakura, V.R. and Ranga Reddy, Y. (in press). Groundwater cyclopoid fauna (Copepoda, Cyclopoida) of peninsular India, with description of eight new species. Zootaxa.

MANUSCRIPT RECEIVED 21 NOVEMBER 2014; ACCEPTED 14 APRIL 2015. 